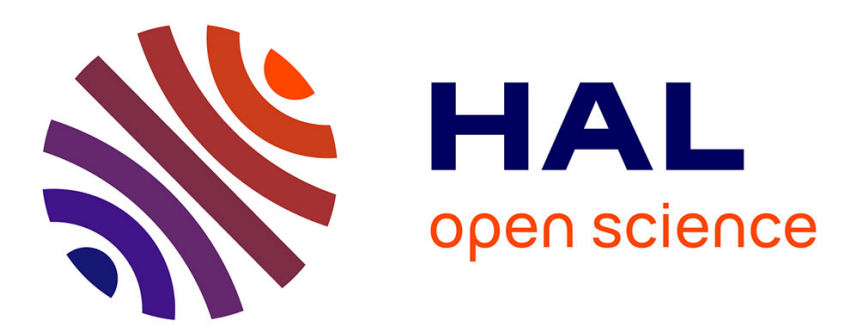

\title{
Toward a Rational Design of 3d-4f Heterometallic Coordination Polymers based on Mixed Valence Copper Centers
}

Carlos Cruz, Francisco Rubio, Diego Venegas-Yazigi, Nathalie Audebrand, Christophe Calers, Evgenia Spodine, Veronica Paredes-Garcia

\section{To cite this version:}

Carlos Cruz, Francisco Rubio, Diego Venegas-Yazigi, Nathalie Audebrand, Christophe Calers, et al.. Toward a Rational Design of 3d-4f Heterometallic Coordination Polymers based on Mixed Valence Copper Centers. Crystal Growth \& Design, 2019, 19 (12), pp.7055-7066. 10.1021/acs.cgd.9b00816 . hal-02438533

\section{HAL Id: hal-02438533 \\ https://hal-univ-rennes1.archives-ouvertes.fr/hal-02438533}

Submitted on 11 Feb 2020

HAL is a multi-disciplinary open access archive for the deposit and dissemination of scientific research documents, whether they are published or not. The documents may come from teaching and research institutions in France or abroad, or from public or private research centers.
L'archive ouverte pluridisciplinaire HAL, est destinée au dépôt et à la diffusion de documents scientifiques de niveau recherche, publiés ou non, émanant des établissements d'enseignement et de recherche français ou étrangers, des laboratoires publics ou privés. 


\title{
Towards a Rational Design of $3 d-4 f$ Heterometallic
}

\section{Coordination Polymers based on Mixed Valence Copper}

\section{Centers}

Carlos Cruz, ${ }^{a, b}$ Francisco Rubio ${ }^{a, b}$ Diego Venegas-Yazigi, ${ }^{b, c}$ Nathalie Audebrand, ${ }^{d}$ Christophe Calers, ${ }^{d}$ Evgenia Spodine ${ }^{b, e}$ and Verónica Paredes-García ${ }^{\star a, b}$

\author{
a Universidad Andrés Bello, Facultad de Ciencias Exactas, Departamento de Ciencias \\ Químicas, Santiago, Chile. \\ b CEDENNA, Santiago, Chile. \\ c Universidad de Santiago de Chile, Facultad de Química y Biología, Departamento de \\ Ciencias de los Materiales, Santiago, Chile \\ d Univ Rennes, CNRS, ISCR (Institut des Sciences Chimiques de Rennes) - UMR 6226, F- \\ 35000 Rennes, France \\ e Universidad de Chile, Facultad de Ciencias Químicas y Farmacéuticas, Departamento de \\ Química Inorgánica y Analítica, Santiago, Chile.
}




\section{ABSTRACT}

In the present work we report two new $\mathrm{Cu} / \mathrm{Cu}^{\mathrm{II}}-\mathrm{Gd}^{\mathrm{III}}$ mixed valence heterometallic coordination polymers $(\mathrm{HCP}), \quad\left[\mathrm{Gd}\left(\mathrm{H}_{2} \mathrm{O}\right)_{4} \mathrm{Cu}^{\mathrm{II}} \mathrm{Cu}^{\mathrm{I}}(\mathrm{IDC})_{2}\right] \quad \mathbf{1}$ and $\left[\mathrm{Gd}_{2}\left(\mathrm{H}_{2} \mathrm{O}\right)_{2}\left(\mathrm{C}_{2} \mathrm{O}_{4}\right)_{2} \mathrm{Cu}^{\mathrm{II}}(\mathrm{IDC})_{2} \mathrm{Cu}_{2}\left(4,4^{\prime}-\right.\right.$ bipy $\left.)\right] \cdot 4.5 \mathrm{H}_{2} \mathrm{O} \quad \boldsymbol{2}$ obtained under solvothermal synthesis using $1 \mathrm{H}$-imidazole-4,5-dicarboxylic acid $\left(\mathrm{H}_{3} \mathrm{IDC}\right)$ as principal $N, O$-bifunctional organic linker. In both compounds, the stabilization of the $\mathrm{Cu}^{\mathrm{I}}$ cations is achieved only by the coordination of $N$-atoms belonging to the organic ligands. While, 1 presents a 2D honeycomb network obtained by the coordination of single organic linker (IDC $\left.{ }^{3-}\right), 2$ contains three different organic ligands ( $\mathrm{IDC}^{3-}, \mathrm{C}_{2} \mathrm{O}_{4}{ }^{2-}$ and 4,4'-bipy), which allow the construction of a $3 \mathrm{D}$ network. From a magnetic point of view, $\mathbf{1}$ and $\mathbf{2}$ behave as simple paramagnets at high temperature, presenting ferromagnetic interactions below $50 \mathrm{~K}$, a positive magnetic coupling constant of $J=0.60 \mathrm{~cm}^{-1}$ and $J=0.22 \mathrm{~cm}^{-1}$ was

obtained for $\mathbf{1}$ and $\mathbf{2}$ respectively. To the best our knowledge $\mathbf{1}$ and $\mathbf{2}$ correspond to the second and third reported examples containing a $\mathrm{Cu}^{\mathrm{I}} / \mathrm{Cu}^{\mathrm{II}}$ mixed valence system assembled with $\mathrm{Gd}^{\mathrm{III}}$ cations, thus enriching the chemistry involved in the $3 d-4 f$ metal-organic materials.

KEYWORDS. Coordination Polymers, Copper, Gadolinium, Mixed-Valence, 3d-4f, Magnetism

\section{INTRODUCTION}

In recent years coordination polymers $(C P)$ have been widely studied in materials science due to their excellent chemical and physical properties, such as porosity, chemical and thermal stability and catalytic activity, making the rational design of new CP a continuous challenge for 
researchers. ${ }^{1,2,3,4}$ In this sense, the combination of two different metal cations in the same structure, such as first row transition ( $3 d)$ and lanthanide ( $4 f$ ) cations has been used as a strategy to obtain new CPs with novel structures and potential applications such as magnetic refrigeration, solid state luminescence and catalysis. $5,6,7,8,9,10$ Compared with the lanthanide series, first row transition metals have a richer chemistry as a consequence of the various oxidation states (from +1 to +7 ) and coordination geometries. Specifically, $\mathrm{Cu}$ and $\mathrm{Cu}^{\prime l}$ cations can adopt a wide variety of coordination geometries (linear, trigonal, tetrahedral, trigonal bipyramid, square base pyramid, octahedral) as compared to other transition metal ions. The coordination plasticity of the copper cations to accommodate different amounts of donor atoms has been also exploited in the construction of $3 d-4 f$ extended structures. ${ }^{11}$

From a magnetic point of view, Cull CPs have been widely studied due to the simple paramagnetic ground state $(S=1 / 2)$ of this cation, which allows magneto-structural correlations. ${ }^{12,13}$ After Bencini et al. ${ }^{14}$ found a compound showing ferromagnetic coupling phenomenon between $\mathrm{Cu}^{\prime \prime}$ and $\mathrm{Gd}^{\prime \prime \prime}$, great efforts have been made to obtain $\mathrm{Cu}^{\prime \prime}-\mathrm{Ln}^{\prime \prime \prime}$ heterometallic compounds with higher dimensionality, seeking for new magnetic materials. ${ }^{15}$ Thus, Cu"l-Ln'II heterometallic networks have been reported in the last decade presenting 
ferromagnetic behavior based on different $\mathrm{N}, \mathrm{O}$-bifunctional organic ligands, such as, iminodiacetic acid, ${ }^{16}$ glycine, ${ }^{17}$ glycinehydroxamic acid, ${ }^{18}$ pyrazoledicarboxylic acid ${ }^{19}$ and benzotriazolecarboxylic acid. ${ }^{20}$

On the other hand, considering that the full shell of $\mathrm{Cu}^{\prime}\left(3 d^{10}\right)$ can be used as an antenna to improve lanthanide luminescence, $\mathrm{Cu}^{\prime}-\mathrm{Ln}^{\text {III }}$ heterometallic coordination polymers (HCPs) have been the focus of research in the solid state light emissive materials. ${ }^{21,22}$ Literature presents a very rich $\mathrm{Cu}^{\prime}-\mathrm{Ln}^{\prime \prime \prime}$ coordination polymer chemistry in which $\mathrm{Cu}^{\prime}$ is stabilized into extended structures using principally functionalized $N$-heterocyclic ligands, such as pyridine and pyrazine. ${ }^{23,24,25,26,27}$ For the majority of the reported $\mathrm{Cu}^{\prime}-\mathrm{Ln}^{\text {III }} \mathrm{CP}$ the stabilization of $\mathrm{Cu}^{\prime}$ is not always done by the coordination of only a $\mathrm{N}$-organic ligand, but also the presence of coordinated halides anions is found. $28,29,30,31,32,33,34$

To the best of our knowledge, the only example of a $3 d-4 f \mathrm{HCP}$ containing $\mathrm{Cu}^{\prime} / \mathrm{Cu}^{\prime \prime}$ has been obtained by Luo et al. $\left[\mathrm{Gd}_{2} \mathrm{Cu}_{2}{ }_{2} \mathrm{Cu}_{5}(\mathrm{IN})_{10}\left(\mu_{2}-\mathrm{Cl}\right)\left(\mu_{2}-\mathrm{OH}_{2}\right)_{2}\left(\mu_{3}-\mathrm{OH}\right)_{2}\right]\left(\mathrm{ClO}_{4}\right)_{2}(\mathrm{HIN}=$ isonicotinic acid), ${ }^{35}$ probably due to the coordination requirements of $\mathrm{Cu}^{\prime}, \mathrm{Cu}^{\prime \prime}$ and $\mathrm{Ln}$ "II cations present in the same structure are not easily satisfied. Furthermore, considering the instability and the poor solubility of the $\mathrm{Cu}^{\prime}$ compounds and the fact that usually compounds based on this cation are 
obtaining for reduction of Cull cation, the possibility to have in the same structure $\mathrm{Cu}^{\prime}, \mathrm{Cu}^{\prime \prime}$ and Ln'II cations it is a great challenge from a synthesis point of view.

In the present work, we report two novel mixed valence $\mathrm{Cu}^{\prime} / \mathrm{Cu}^{\prime \prime}-\mathrm{Ln}^{\prime \prime \prime} \quad \mathrm{HCP}$, $\left[\mathrm{Gd}\left(\mathrm{H}_{2} \mathrm{O}\right)_{4} \mathrm{Cu}^{\prime \prime} \mathrm{Cu}^{\prime}(\mathrm{IDC})_{2}\right] 1$ and $\left[\mathrm{Gd}_{2}\left(\mathrm{H}_{2} \mathrm{O}\right)_{2}\left(\mathrm{C}_{2} \mathrm{O}_{4}\right)_{2} \mathrm{Cu}^{\prime \prime}(\mathrm{IDC})_{2} \mathrm{Cu}_{2}\left(4,4^{\prime}\right.\right.$-bipy)] $4.5 \mathrm{H}_{2} \mathrm{O}$ 2, obtained using $1 \mathrm{H}$-imidazole-4,5-dicarboxylic acid $\left(\mathrm{H}_{3} \mathrm{IDC}\right)$ as the principal $\mathrm{N}, \mathrm{O}$-bifunctional organic linker. $\mathrm{H}_{3} I D C$ has been already used by our research group, proving to be an excellent ligand to obtain new $3 d-4 f$ compounds, giving rise to HCP including a 2D Cull-Gd"II network, ${ }^{36} \mathrm{Co}^{\text {II-G }}$-GIII $3 \mathrm{D}$ frameworks ${ }^{37}$ and recently two $3 d-\mathrm{Ce}^{\text {III }}$ compounds $\left(3 d=\mathrm{Cu}^{\prime \prime}, \mathrm{Co}^{\prime \prime}\right) \cdot{ }^{38}$ In the present work, two new HCP were prepared under solvothermal conditions. 1 presents a 2D structure showing a honeycomb type arrangement, while 2 corresponds to a 3D structure. Structural, thermal stability, spectroscopic and magnetic properties are discussed in detail.

\section{EXPERIMENTAL SECTION}

All reagents and solvents used to obtain 1 and 2 were of p.a. quality and were used without any previous purification. Figure 1, summarizes the synthesis of the two compounds.

\subsection{Synthesis of $\left[\mathrm{Gd}\left(\mathrm{H}_{2} \mathrm{O}\right)_{4} \mathrm{Cu}^{\prime \prime} \mathrm{Cu}^{\prime}(\mathrm{IDC})_{2}\right] 1$}


A mixture of $\mathrm{Cu}\left(\mathrm{NO}_{3}\right)_{2} \cdot 3 \mathrm{H}_{2} \mathrm{O}(0.5 \mathrm{mmol}), \mathrm{Gd}_{2} \mathrm{O}_{3}(0.13 \mathrm{mmol}), \mathrm{H}_{3} \mathrm{IDC}(0.5 \mathrm{mmol})$ and $\mathrm{H}_{2} \mathrm{C}_{2} \mathrm{O}_{4} \cdot 2 \mathrm{H}_{2} \mathrm{O}(0.5 \mathrm{mmol})$ in $14 \mathrm{~mL}$ of $\mathrm{H}_{2} \mathrm{O}$ and $1 \mathrm{~mL}$ of ethanol $(\mathrm{EtOH})$ was treated with $80 \mu \mathrm{L}$ (0.6 mmol) of triethylamine (TEA). The resultant mixture was placed in a $23 \mathrm{~mL}$ Teflon-lined stainless-steel autoclave vessel and heated at $165^{\circ} \mathrm{C}$ under self-generated pressure for 4 days. Finally, the reaction vessel was cooled down to room temperature at $3^{\circ} \mathrm{C} / \mathrm{h}$ rate (48 hours); olivegreen needle-like crystals of 1 , suitable for X-ray diffraction, were separated by filtration. Although oxalic acid is not present in the final product, without the addition of this reagent 1 is not obtained. MW: $662.59 \mathrm{~g} / \mathrm{mol}$. Yield of $62 \%$, based on the lanthanide salt. Calculated analysis for $\mathrm{Cu}_{2} \mathrm{GdC}_{10} \mathrm{H}_{10} \mathrm{~N}_{4} \mathrm{O}_{12}(\%): \mathrm{C}, 18.13 \% ; \mathrm{H}, 1.52 \% ; \mathrm{N}, 8.46 \%$. (\%) Found: $\mathrm{C}, 18.76 \% ; \mathrm{H}, 1.56 \%$; $\mathrm{N}, 7.72 \%$.

\subsection{Synthesis of $\left[\mathrm{Gd}_{2}\left(\mathrm{H}_{2} \mathrm{O}\right)_{2}\left(\mathrm{C}_{2} \mathrm{O}_{4}\right)_{2} \mathrm{Cu}^{\prime \prime}(\mathrm{IDC})_{2} \mathrm{Cu}_{2}\left(4,4^{\prime}-\right.\right.$-bipy $\left.)\right] \cdot 4.5 \mathrm{H}_{2} \mathrm{O} 2$}

2 was obtained using the same procedure as that of synthesis of 1 but adding 4,4'-bipyridine $(0.5 \mathrm{mmol})$ to the mixture; olive-green prismatic crystals of 2 , suitable for $\mathrm{X}$-ray diffraction were mechanically separated from the reaction medium. MW: $1260.68 \mathrm{~g} / \mathrm{mol}$. Yield: $13 \%$, based on the lanthanide salt. Calculated analysis for $\mathrm{Cu}_{3} \mathrm{Gd}_{2} \mathrm{C}_{24} \mathrm{H}_{23} \mathrm{~N}_{6} \mathrm{O}_{22.5}(\%)$ : C, 22.86; $\mathrm{H}, 1.84 ; \mathrm{N}, 6.67$. (\%) Found: C, 22.52; H, 1.76; N, 7.06. 


\subsection{X-ray Data Collection and Structure Determination}

Single-crystal X-ray diffraction data of compound 1 and 2 were collected at $150 \mathrm{~K}$ on a D8

VENTURE Bruker AXS diffractometer and processed with the APEX3 program suite, ${ }^{39}$ using Mo-Ka as X-ray wavelength. Frame integration and data reduction were carried out with the program SAINT, ${ }^{40}$ and SADABS was employed for multiscan-type absorption corrections. ${ }^{41}$

Using the Olex $2^{42}$ package, the structures were solved with the ShelXT ${ }^{43}$ structure solution program using Dual Space Methods and refined with the ShelXL ${ }^{44}$ refinement package, using least squares minimization based on $\mathrm{F}^{2}$. Crystallographic data, details on data collections and refinement parameters of the crystal structure are summarized in Table 1. Structure drawings have been made with TOPOs software. ${ }^{45}$ Additional data concerning the crystals and the refinement parameters are detailed in the supporting information (Table S1).

All hydrogen atoms where properly localized, expect the one belonging to O4W in 1 and O1W, $\mathrm{O} 2 \mathrm{~W}, \mathrm{O} 3 \mathrm{~W}, \mathrm{O} 4 \mathrm{~W}$ and $\mathrm{O} 9$ in 2 . Nevertheless, all hydrogen atoms were considered in the final formula. Additionally, crystallization $\mathrm{H}_{2} \mathrm{O}$ molecules $\mathrm{O} 1 \mathrm{~W}, \mathrm{O} 2 \mathrm{~W}, \mathrm{O} 3 \mathrm{~W}$ and $\mathrm{O} 4 \mathrm{~W}$ located into the interstitial spaces of 2 present disorder and were modelled by parts, giving a total amount of four 
water molecules per unity of complex. The amount of $\mathrm{H}_{2} \mathrm{O}$ of crystallization in the bulk material was obtained experimentally using thermogravimetric analysis.

In situ temperature-dependent X-ray diffraction (TDXD) was performed for 1 in a flux of $\mathrm{N}_{2}$ with a Malvern Panalytical Empyrean powder diffractometer, using a germanium incident-beam graphite monochromator, selecting the radiation $\mathrm{Cu} \mathrm{K \alpha _{1 }}$, and a PIXcel 3D detector and equipped with an Anton Paar HTK1200 oven chamber. In situ measurements were carried out at various constant temperatures from ambient temperature until $800^{\circ} \mathrm{C}$. Between each measurement step, the sample was heated at a rate of $1.0{ }^{\circ} \mathrm{C} \mathrm{min}-1$ to the desired temperature. Diffraction patterns were collected over the angular range $5-60^{\circ}(2 \theta)$ with a counting time of $40 \mathrm{~s} \mathrm{step}^{-1}$ and with a step length of $0.013^{\circ}(2 \theta)$.

\subsection{Magnetic Measurements}

Magnetic measurements were carried out using a Quantum Design Dynacool Physical Properties Measurement System (PPMS), equipped with a Vibrating Sample Magnetometer (VSM). The $d c$ data were collected under an external applied field of $1 \mathrm{kOe}$ in the $1.8-300 \mathrm{~K}$ temperature range. Isothermal magnetizations were performed between 0 and $\pm 90 \mathrm{kOe}$ at temperatures varying from 1.8 to $8 \mathrm{~K}$. All Magnetic measurement were performed under crystalline power samples in 
plastic sampleholder. Diamagnetic corrections (estimated from Pascal constants) were considered. 46

\subsection{Thermogravimetric analysis}

Thermogravimetric analysis was performed on a Mettler Toledo TGA/DSC STAR system. The samples were introduced in an alumina holder and heated under a $\mathrm{N}_{2}$ atmosphere from room temperature to $900{ }^{\circ} \mathrm{C}$ with a heating rate of $5{ }^{\circ} \mathrm{C} / \mathrm{min}$.

\subsection{Spectroscopic measurements}

UV-Vis-NIR spectra were obtained on a Perkin Elmer Lambda 1050 spectrophotometer UVVis/NIR, equipped with a Perkin Elmer $150 \mathrm{~mm}$ InGaAs Integrating sphere. The measurements were carried out in the $200-1200 \mathrm{~nm}$ range using the solid sample without any support.

\section{RESULTS AND DISCUSSION}

3.1 Structural Characterization of $\left[\mathrm{Gd}\left(\mathrm{H}_{2} \mathrm{O}\right)_{4} \mathrm{Cu}^{\prime \prime} \mathrm{Cu}^{\prime}(\mathrm{IDC})_{2}\right] \quad 1 \quad$ and $\left[\mathrm{Gd}_{2}\left(\mathrm{H}_{2} \mathrm{O}\right)_{2}\left(\mathrm{C}_{2} \mathrm{O}_{4}\right)_{2} \mathrm{Cu}^{\prime \prime}(\mathrm{IDC})_{2} \mathrm{Cu}_{2}\left(4,4^{\prime}-\right.\right.$ bipy $\left.)\right] \cdot 4.5 \mathrm{H}_{2} \mathrm{O} 2$

X-ray diffraction analysis reveals that compound 1 crystallizes in the $P \overline{1}$ triclinic space group, presenting an asymmetrical unit with two different copper $\left(\mathrm{Cu}^{\prime}, \mathrm{Cu}^{\prime \prime}\right)$ and one gadolinium cations, four water molecules and two independent fully deprotonated IDC ${ }^{3-}$ species. Both IDC ${ }^{3-}$ anions 
bind two copper and one gadolinium cations, at the same time presenting a $\eta^{3}-\mathrm{K} N-\mathrm{K} O^{\prime}, O^{\prime \prime}-\mathrm{\kappa} O^{\prime \prime \prime}, N^{\prime}$

coordination mode (Figure 2a). Cu1 cations are bonded to two $\mathrm{IDC}^{3-}$ anions, which are connected in a monodentate mode through $\mathrm{N}$ atoms with a trans conformation, with bond distances of Cu1-N2=1.872(2) $\AA$ and Cu1-N3=1.880(2) $\AA$. Cu1 is also weakly interacting with the two carboxylates groups belonging to each IDC ${ }^{3-}$ ligand with $\mathrm{Cu}-\mathrm{O}$ bond distances of $\mathrm{Cu} 1-$ $\mathrm{O}=2.576(2) \AA$ and $2.781(2) \AA$ (Figure 3a). Meanwhile, Cu2 cations present a coordination environment formed by two IDC ${ }^{3-}$ anions (Figure 3b) bonded by N-imidazole and O-carboxylate, forming two independent NCCO five member rings, with bond distances of Cu2-N1=1.933(2) $\AA$, Cu2-N4=1.922(2) $\AA$, Cu2-O1=1.973(2) $\AA$, Cu2-O5=1.976(2) $\AA$ and $\mathrm{N}-\mathrm{Cu}-\mathrm{O}$ angles of 98.99(9) ${ }^{\circ}$ (N1-Cu2-O5) and 82.44(9) $)^{\circ}$ (N4-Cu2-O5). Taking into account the bond distance for both copper cations, Cu1 should be better described with a $\mathrm{CuN}_{2}$ environment, having a linear geometry with a N-Cu-N angle of $177.28(1)^{\circ}$. In the case of $\mathrm{Cu} 2$, the cation can be well described with a $\mathrm{CuN}_{2} \mathrm{O}_{2}$ environment presenting a distorted square plane geometry, since the $\mathrm{Cu}-\mathrm{O}$ and Cu- $\mathrm{N}$ bond distances are comparable in length, and $\mathrm{N}-\mathrm{Cu}-\mathrm{O}$ angles are close to $90^{\circ}$. Furthermore, comparing the bond distances and coordination geometries of the two types of copper cations, it is possible to infer that Cu1 should present a $1+$ oxidation state, while Cu2 
must present a 2+ oxidation state, which is in perfect agreement with the charge balance of the framework.

On the other hand, $\mathrm{Gd} 1$ presents a $\mathrm{GdO}_{8}$ coordination sphere, with $\mathrm{Gd}-\mathrm{O}$ bond distances in the range of $2.558(2)-2.260(2) \AA$, formed by two $\mathrm{K} O^{\prime}, \mathrm{O}^{\prime \prime}-\mathrm{IDC} \mathrm{C}^{3-}$ species, bonded by two Ocarboxylate atoms generating two independent seven member rings. The coordination around Gd'II cations is completed by four $\mathrm{H}_{2} \mathrm{O}$ molecules (Figure 3c), leading to a bicapped trigonal prism geometry, corroborated by a continuous shape measurement using the SHAPE software. ${ }^{47}$

Furthermore, 1 presents a honeycomb topology formed by heterometallic $\left[\mathrm{Gd}_{2} \mathrm{Cu}_{2} \mathrm{Cu}_{2}{ }_{2}\right]$ hexagonal moieties (Figure 4a). Each corner of the $\left[\mathrm{Gd}_{2} \mathrm{Cu}_{2}{ }_{2} \mathrm{Cu}_{2}{ }_{2}\right]$ hexagon is formed by an IDC ${ }^{3-}$ anion connected to each other by one Gd'II and one copper cation (Cu1 or Cu2), forming an alternating Gd"I'-Cull-Cu' ordering. The hexagonal honeycomb topology is shown more clearly in a simplified structure in figure $4 b$, in which it is easy to see how the cations $\mathrm{Cu}^{\prime}, \mathrm{Cu}^{\prime \prime}$ and $\mathrm{Gd}^{\prime \prime \prime}$ are behaving as linear nodes, while the IDC ${ }^{3-}$ linker can be defined as a tritopic trigonal plane spacer. Moreover, it is interesting to note how of the $\mathrm{H}$-bonding produced by the $\mathrm{H}_{2} \mathrm{O}$ molecules coordinated to Gd cation are the key of the resulting crystal packing of the layers. In this sense 
if we only consider the arrangement of the four water molecules around of Gd"I belonging to one layer, it is possible to observe how this disposition produces two types of interaction between the adjacent layers. Thus, the three water molecules forming a tripod are localized in such way that they are inserted in the hexagons of the cavity of one adjacent layer (Figure 4c), interacting by $\mathrm{H}$-bonding with the carboxylate groups of IDC $^{3-}$ (Table 2 for $\mathrm{H}$-bonding). This interaction produces a displaced-layer stacking, with each hexagonal cavity filled by a water-tripod avoiding the existence of porosity in the structure, defining a double-layer arrangement. Furthermore, the last $\mathrm{H}_{2} \mathrm{O}$ molecule coordinating the $\mathrm{Gd}^{\text {IIII }}$ cations is pointing just opposite to the former watertripod, allowing a second $\mathrm{H}$-bond interaction between the double-layers (Table 2 for $\mathrm{H}$-bonding), giving the final crystal packing (Figure 4d).

Since $\mathrm{Cu} 1$ and $\mathrm{Cu} 2$ cations have an unsaturated coordination sphere (linear and square plane respectively) in the $2 \mathrm{D}$ structure of $\left[\mathrm{Gd}\left(\mathrm{H}_{2} \mathrm{O}\right)_{4} \mathrm{Cu}^{\prime \prime} \mathrm{Cu}^{\prime}(\mathrm{IDC})_{2}\right] 1$, this heterometallic compound is a good candidate as starting material to generate a 3D coordination polymer using a linear ligand such as 4,4'-bipyridine as interlayer linker (two step synthesis). However, by adding the 4,4'bipyridine ligand in the same reaction media used for 1 (one pot synthesis) a new compound 2 
was formed. This compound is also a Cu'-Cull-Gd"II mixed valence HCP, but now presenting a

3D network $\left[\mathrm{Gd}_{2}\left(\mathrm{H}_{2} \mathrm{O}\right)_{2}\left(\mathrm{C}_{2} \mathrm{O}_{4}\right)_{2} \mathrm{Cu}^{\prime \prime}(\mathrm{IDC})_{2} \mathrm{Cu}_{2}(4,4\right.$ '-bipy $\left.)\right] \cdot 4.5 \mathrm{H}_{2} \mathrm{O}$.

Compound 2 crystallizes in the $P \overline{1}$ triclinic space group and presents a $3 \mathrm{D}$ coordination framework, with an asymmetrical unit formed by one and a half copper and one gadolinium cations, one water molecule, one independent fully deprotonated IDC ${ }^{3-}$ species, one oxalate anion $\left(\mathrm{C}_{2} \mathrm{O}_{4}{ }^{2-}\right)$ and half 4,4'-bipyridine (4,4'-bipy). Additionally, the compound also presents disordered crystallization $\mathrm{H}_{2} \mathrm{O}$ molecules. The coordination mode of the IDC ${ }^{3-}$ species is the same as the one observed in $1, \eta^{3}-\kappa N-\kappa O^{\prime}, O^{\prime \prime}-k O^{\prime \prime \prime}, N^{\prime}($ Figure 2a). The 4,4'-bipy molecule serves as a ditopic ligand, connecting two copper centers in a $\mu_{2}-\mathrm{K} N-\mathrm{k} N^{\prime}$ coordination fashion, while the $\mathrm{C}_{2} \mathrm{O}_{4}{ }^{2-}$ anions coordinate $\mathrm{Gd}$ "III in $\mu_{2}-O, O^{\prime}-O^{\prime \prime}, O^{\prime \prime \prime}$ mode (Figure $2 \mathrm{~b}-\mathrm{c}$ ). Similarly, as in 1 , to achieve the electron neutrality of the network and balance the negative charge belonging to IDC $^{3-}$ and $\mathrm{C}_{2} \mathrm{O}_{4}{ }^{2-}$ species 2 must present copper cations in two different oxidation states. Cu1 presents a $\mathrm{CuN}_{2} \mathrm{O}_{2}$ environment formed by two IDC ${ }^{3-}$ anions (Figure $5 \mathrm{a}$ ) coordinated by $\mathrm{N}$ imidazole and O-carboxylate, forming two NCCO five-member rings, with Cu1-O1=1.962(3) $\AA$ and $\mathrm{Cu} 1-\mathrm{N}=\AA \AA$, Cu1-N1=1.915(3) Å bond length distances. Moreover, since the $\mathrm{N}-\mathrm{Cu}-\mathrm{O}$ angles are near to $90^{\circ}\left(\mathrm{N} 1-\mathrm{Cu} 1-\mathrm{O} 1=96.01(12)^{\circ}, \mathrm{N} 1-\mathrm{Cu} 1-\mathrm{O} 1=83.99(12)^{\circ}\right)$, the geometry around Cu1 
can be well defined as square planar. On the other hand, $\mathrm{Cu} 2$ is bonded to one IDC ${ }^{3-}$ anion and one 4,4'-bipy, connected by means of nitrogen atoms, presenting Cu2-N2=1.846(3) A, Cu2N3=1.852(3) A bond lengths. Cu2 is also weakly interacting with one carboxylate group belonging to IDC ${ }^{3-}$ with a distance of Cu2-O4=2.627(2) $\AA$ (Figure 5b). Furthermore, the N2-Cu2$\mathrm{N} 3$ angle is $178.71(14)^{\circ}$, while the $\mathrm{N}-\mathrm{Cu} 2-\mathrm{O} 4$ is $105.58(12)^{\circ}$ and $74.87(10)^{\circ}$; therefore the environment around $\mathrm{Cu} 2$ can be defined as lineal $\mathrm{CuN}_{2}$.

Considering the type of coordination environment, Cu1 can be assigned a 2+ oxidation state with a square planar geometry, while $\mathrm{Cu} 2$ presents a $1+$ oxidation state with linear geometry. Meanwhile, $\mathrm{Gd} 1$ presents a $\mathrm{GdO}_{9}$ environment formed by two $\mathrm{IDC}^{3-}$ molecules coordinated by one $\left(\mathrm{K} O, \mathrm{O}^{\prime}-\mathrm{IDC} \mathrm{C}^{3-}\right)$ and two $\left(\mathrm{K}^{\prime}, \mathrm{O}^{\prime \prime}-\mathrm{IDC} \mathrm{C}^{3-}\right)$ carboxylate groups. Also, two $\mathrm{K} O, \mathrm{O}^{\prime} \mathrm{k} \mathrm{O}^{\prime \prime}, \mathrm{O}^{\prime \prime \prime}-\mathrm{C}_{2} \mathrm{O}_{4}{ }^{2-}$ anions and one $\mathrm{H}_{2} \mathrm{O}$ molecules are bonded to $\mathrm{Gd} 1$ centers with $\mathrm{Gd}-\mathrm{O}$ bond distance in the range of $2.547(2)-2.387(2) \AA$, leading to a capped square antiprism geometry, corroborated by an continuous shape measurement using the SHAPE software (Figure $5 \mathrm{c}$ ). ${ }^{47}$ Moreover, the 3D extended structure of 2 can be disassembled in two different homometallic substructures. The first one corresponding to a cationic 1D substructure formed by $\left[\mathrm{Gd}_{2}\left(\mathrm{H}_{2} \mathrm{O}\right)_{2}\left(\mathrm{C}_{2} \mathrm{O}_{4}\right)_{2}\right]^{2+}$ building units, in which the $\mathrm{Gd}^{\text {III }}$ centers are bridged by two different oxalate 
anions (Figure 6a) forming a zigzag chain along $c$ axis. Meanwhile, the second substructure corresponds to anionic mixed valence $\mathrm{Cu}^{\prime} / \mathrm{Cu}^{\prime \prime}$ linear chains, formed by $\left[\mathrm{Cu}^{\prime \prime}(\mathrm{IDC})_{2} \mathrm{Cu}_{2}^{\prime}\left(4,4^{\prime}-\right.\right.$ bipy)] $]^{2-}$ as building units (Figure 6b). Figure $6 \mathrm{c}$ depicts the cross-linked connectivity between both homometallic substructures, showing clearly the role of the IDC ${ }^{3-}$ anion in the assembly of both homometallic chains. The IDC ${ }^{3-}$ anion of the $\mathrm{Cu}^{\prime} / \mathrm{Cu}^{\text {II }}$ chains anchors $\mathrm{Gd}^{\text {IIII }}$ centers of two adjacent $\left[\mathrm{Gd}_{2}\left(\mathrm{H}_{2} \mathrm{O}\right)_{2}\left(\mathrm{C}_{2} \mathrm{O}_{4}\right)_{2}\right]^{2+}$ chains, with a $\mathrm{KO}, \mathrm{O}^{\prime}$ IDC ${ }^{3-}$ coordination fashion, generating the 3D framework. As stated in the introduction section, the unique example of a $3 d-4 f$ mixed valence compound is $\left[\mathrm{Gd}_{2} \mathrm{Cu}_{2}{ }_{2} \mathrm{Cu}_{5}(\mathrm{IN})_{10}\left(\mu_{2}-\mathrm{Cl}\right)\left(\mu_{2}-\mathrm{OH}_{2}\right)_{2}\left(\mu_{3}-\mathrm{OH}\right)_{2}\right]\left(\mathrm{ClO}_{4}\right)_{2}$, which was synthesized by hydrothermal reaction of isonicotinic acid (HIN) as bifunctional ligand, $\mathrm{Gd}_{2} \mathrm{O}_{3}$ and $\mathrm{CuCl}_{2}$ as metal precursors in the presence of $\mathrm{HClO}_{4}$ and $\left(\mathrm{NH}_{4}\right) \mathrm{HCOO}$, giving a 3D structure constructed by the self-assembly of 12 -connected $\mathrm{Gd}^{\prime \prime \prime}{ }_{2} \mathrm{Cu}_{2}{ }_{2}$ subunits interconnected by $\mathrm{Cu}^{\prime}-\mathrm{IN}^{-}$ fragments. ${ }^{35}$ In the case of 1 and 2 , the inclusion of a $\mathrm{Cu}^{\prime} / \mathrm{Cu}^{\prime \prime}$ mixed-valence compound was also achieved by the partial hydrothermal reduction of a cupric salt precursor. Furthermore, it has been reported by Truong et al. that under hydrothermal condition oxalic acid can act as reducing agent; therefore, this reactive could be the responsible for the reduction of copper salt under autogenerated pressure. This could be related with the fact that if oxalic acid is not present 
as reagent in the corresponding synthesis, $\mathbf{1}$ and $\mathbf{2}$ were not obtained. Moreover, Truong et al. propose that oxalic acid degrades to carbon monoxide or carbon dioxide and that a copper oxalate complex act as intermediate in the $\mathrm{Cu}^{\prime} / \mathrm{Cu}^{\prime \prime}$ reduction process. ${ }^{48}$ Another interesting feature in the compound reported by Luo et al. is the presence of $\mathrm{Cu}^{\prime}$ centers in linear $\mathrm{CuO}_{2}$ and $\mathrm{CuN}_{2}$ environment, similar to that of 2. Linear conformations are common in other $d^{10}$ coordination polymers such as $\mathrm{Au}^{\prime} 49,50$ and $\mathrm{Ag}^{\prime},{ }^{51,52}$ however $\mathrm{Cu}^{\prime}$ is usually reported presenting trigonal'53,54 and tetrahedral ${ }^{55,56}$ geometries, while $\mathrm{Cu}^{\prime} / \mathrm{Cu}^{\prime \prime}$ and $\mathrm{Cu}^{\prime} \mathrm{CPs}$ containing linear $\mathrm{Cu}^{\prime}$ are more scarce. ${ }^{57}$ On the other hand, according to the Robin and Day classification, 1 and 2 can be described as Class I mixed valence compounds, since in both structures the $\mathrm{Cu}^{\prime}$ and $\mathrm{Cu}^{\prime \prime}$ cations can be identified by the difference in their coordination geometries. ${ }^{58,59}$

Additionally, another structural comparison can be made between 1 and two 3D frameworks $\left\{\left[\mathrm{Zn}_{3}(\mathrm{IDC})_{2}\left(4,4^{\prime}-\text { bipy }\right)_{3}\right] \cdot\left(4,4^{\prime} \text {-bipy }\right) \cdot 8 \mathrm{H}_{2} \mathrm{O}\right\}_{\mathrm{n}}$ obtained by Lu et al. ${ }^{60}$ and $\left\{\left[\mathrm{Co}_{3}(\mathrm{IDC})_{2}\left(4,4^{\prime}-\right.\right.\right.$ bipy) $\left.\left.)_{3}\right] \cdot 6 \mathrm{H}_{2} \mathrm{O} \cdot \mathrm{DMF}\right\}_{n}$ obtained by Wang et al. ${ }^{61}$ It is quite surprising that although these both frameworks are constructed only by $\mathrm{M}^{\prime \prime}$ cations $\left(\mathrm{M}^{\prime \prime}=\mathrm{Zn}^{\|}\right.$and $\left.\mathrm{Co}^{\prime \prime}\right)$, presents $\left[\mathrm{M}_{3}(\mathrm{IDC})_{2}\right]_{\mathrm{n}} 2 \mathrm{D}$ sub-structures with exactly the same honeycomb topology as the one observed in 1. In both cases, the layers are formed by $\mathrm{M}^{\prime \prime}$ cations, connected through alternating imidazolate $\mu_{2}-\kappa N, N^{\prime}$ - 
IDC ${ }^{3-}$ and anti-anti $\mu_{2}-\kappa O, O^{\prime}$ IDC ${ }^{3-}$ carboxylate, which are further pillared by $\mu_{2}-N, N^{\prime}-4,4^{\prime}-$ bipy connections, presenting hexagonal cavities into the 3D CP. This fact suggests that the property of generate $2 \mathrm{D}$ structures with honey comb topology is an intrinsic property of the IDC ${ }^{3-}$ ligands, being independent of the metal ions used.

3.2 Thermal stability of $\left[\mathrm{Gd}\left(\mathrm{H}_{2} \mathrm{O}\right)_{4} \mathrm{Cu}^{\prime \prime} \mathrm{Cu}^{\prime}(\mathrm{IDC})_{2}\right] 1$ and $\left[\mathrm{Gd}_{2}\left(\mathrm{H}_{2} \mathrm{O}\right)_{2}\left(\mathrm{C}_{2} \mathrm{O}_{4}\right)_{2} \mathrm{Cu}^{\prime \prime}(\mathrm{IDC})_{2} \mathrm{Cu}_{2}\left(4,4^{\prime}-\right.\right.$ bipy)] $4.5 \mathrm{H}_{2} \mathrm{O} 2$

Thermogravimetric analysis between 25 and $900^{\circ} \mathrm{C}$ under $\mathrm{N}_{2}$ atmosphere was performed to characterize the thermal stability of 1 and 2 (inset Figure 7). Thermogram of 1 shows two consecutive weight losses, between $95-220^{\circ}(7.56 \mathrm{wt} \%)$ and $220-290^{\circ} \mathrm{C}(2.75 \mathrm{wt} \%)$ attributed to the release of the four coordinated water molecules (10.3 wt\%). After these two steps, a third weight loss of $27.9 \%$ is observed from $350^{\circ} \mathrm{C}$, indicating the thermal decomposition of the framework. On the other hand, 2 presents a first weight loss between $40-210{ }^{\circ} \mathrm{C}$ with a value of 6.38 wt\%, which can be associated to the thermal outflow of the 4.5 crystallization $\mathrm{H}_{2} \mathrm{O}$ molecules, occluded in the interstices of the 3D structure of 2 . The percentage associated with this weight loss is a little higher than the obtained from X-ray diffraction analysis $\left(4.0 \mathrm{H}_{2} \mathrm{O}\right.$ molecules). Later, three consecutive smooth weight losses are observed between $210^{\circ}$ and 
$330^{\circ} \mathrm{C}$ with a total percentage of $39.17 \mathrm{wt} \%$, associated with the thermal decomposition of the framework. The stability of this type of networks can be associated to the hydrogen bonding interactions between the water molecules and carboxylate oxygen atoms belonging to organic linkers, stabilizing significantly the network packing, ${ }^{62,63,64}$ Furthermore, in 3D frameworks the guest molecule evacuation from interstitial cavities can be accompanied by collapse of the structure of the extended networks. ${ }^{65,66}$

In situ temperature-dependent X-ray diffraction (TDXD) was performed for the 1 framework to establish structural correlations with TG analysis (Figure 7). Comparing the experimental 1 powder diffractogram with the calculated pattern from single crystal (Figure S1), it is clear that the 1 powder phase is pure. Unfortunately, it was no possible to perform the TDXD of 2 , due to the low yield in the synthesis of this compound.

When 1 is heated from room temperature to $290^{\circ} \mathrm{C}$ under $\mathrm{N}_{2}$ atmosphere, TDXD experiments show that the diffraction pattern is maintained, proving that the release of the coordination $\mathrm{H}_{2} \mathrm{O}$ molecules does not affect the structural integrity of 1 . Until $300^{\circ} \mathrm{C}$ no changes are registered in TDXD, showing that the framework is stable even after the dehydration process. From $300^{\circ} \mathrm{C}$ to $350^{\circ} \mathrm{C}$ the principal diffraction peaks of 1 begin to disappear. Considering that the TG analysis 
shows a non-significant weight loss in this temperature range, the loss of the crystallinity process can be suggested. Moreover, above $450^{\circ} \mathrm{C}$ new peaks start to appear at higher $2 \theta$ values, indicating that new crystalline phases are formed. The peaks position at $43.3^{\circ}$ and $50.4^{\circ}$ correlate well with (111) and (200) diffraction planes of metallic $\mathrm{Cu}^{0}$ phase (ICDD PDF2 No. 01-0892838), ${ }^{67,68}$ indicating that the reduction of $\mathrm{Cu}^{\prime} / \mathrm{Cu}^{\prime \prime}$ cations to $f c c-\mathrm{Cu}^{0}$ is taking place. Starting from $650^{\circ} \mathrm{C}$, new peaks at $28.6^{\circ}, 33.1^{\circ}$ and $47.5^{\circ}$ can be associated to the (222), (400) and (440) diffraction planes of cubic- $\mathrm{Gd}_{2} \mathrm{O}_{3}$ (ICDD PDF2 No. 03-065-3181). ${ }^{69}$

\subsection{Spectroscopic characterization}

UV-Vis-NIR electronic spectra are interesting to complement the characterization of 1 and 2. Cull complexes show $d-d$ absorption bands in the Vis-NIR range, while the complete $3 d$ shell in $\mathrm{Cu}^{\mathrm{l}}$ compounds prevents metal-centered electronic transitions. At the same time, $\mathrm{Cu}^{\mathrm{l}}$ compounds may present metal to ligand charge transfer (MLCT), which are generally more intense and at higher energies as compared to the $d-d$ transitions. ${ }^{70}$ Figure S2 shows the solid state UV-Vis-NIR spectra of both compounds in the region between 200 and $850 \mathrm{~nm}$. A broad band covering almost all the studied region is observed in both spectra. At lower wavelengths, a band centered near $260 \mathrm{~nm}$ can be associated to a ligand-centered absorption, belonging to 
the organic species. ${ }^{71}$ At higher wavelengths, a band centered at 582 and $535 \mathrm{~nm}$ for 1 and 2 , respectively can be related with the overlapping of the three spin allowed $d-d$ transitions of Cull centers in a square planar geometry, $d_{x z} / d_{y z} \rightarrow d_{x^{2}-y^{2}}, d_{z^{2}} \rightarrow d_{x^{2}-y^{2}}$ and $d_{x y} \rightarrow d_{x^{2}-y^{2} .}{ }^{72}$ An additional band can be observed at 376 and $395 \mathrm{~nm}$ for 1 and 2 associated to metal to ligand charge transfer between $\mathrm{Cu}^{\prime}$ centers and the heterocyclic organic ligands. ${ }^{73}$ These results also permit to corroborate the existence of a mixed-valence $\mathrm{Cu}^{\prime} / \mathrm{Cu}^{\prime \prime}$ system in $\mathbf{1}$ and $\mathbf{2}$.

In compound 1 and $\mathbf{2}$, two separate emission process could be expected, one of them in the UV region corresponding to a $f$ - $f$ transition belonging of $\mathrm{Gd}^{\mathrm{III}}$ cation, ${ }^{74}$ and the other one an emission of the $\mathrm{Cu}^{\prime}$-ligand fragment which should appear in the visible region. ${ }^{21,22}$ To explore the luminescence properties of 1 and 2 , solid state emission spectra were recorded at room temperature using as excitation the energy maxima observed in the absorption spectra. Nevertheless, no emission was observed at the studied conditions. These results could be related with the fact that in $\mathbf{1}$ and $\mathbf{2}$ the fexcited states of Gd"I are above of the excited state of the organic ligand, inhibiting a possible ligand $\rightarrow G d$ antenna effect. ${ }^{75,76}$ On the other hand, the Cull cations in 1 and 2 could be acting as a quencher of the Cu'-ligand emission, since the 
divalent copper cation presents a broad intense $d-d$ absorption band in the Vis-NIR regions, which can deactivate emissive excited states in non-radiative pathways. ${ }^{77}$

\subsection{Magnetic Properties}

Figure 8 shows $\chi_{\mathrm{m}}^{\top} \quad$ vs $\quad \mathrm{T}$ plots for $\left[\mathrm{Gd}\left(\mathrm{H}_{2} \mathrm{O}\right)_{4} \mathrm{Cu}^{\prime \prime} \mathrm{Cu}^{\prime}(\mathrm{IDC})_{2}\right], \quad 1$ and $\left[\mathrm{Gd}_{2}\left(\mathrm{H}_{2} \mathrm{O}\right)_{2}\left(\mathrm{C}_{2} \mathrm{O}_{4}\right)_{2} \mathrm{Cu}^{\prime \prime}(\mathrm{IDC})_{2} \mathrm{Cu}_{2}\left(4,4^{\prime}-\right.\right.$ bipy $\left.)\right] \cdot 4.5 \mathrm{H}_{2} \mathrm{O} 2$ between $300-1.8 \mathrm{~K}$ at $1 \mathrm{kOe}$. The $\chi_{\mathrm{m}} \mathrm{T}$ value observed at $300 \mathrm{~K}$ for 1 and 2 is 8.4 and $16.0 \mathrm{emu} \mathrm{K} \mathrm{mol}^{-1}$ respectively, which is close to the expected value for non-interacting paramagnetic centers in both frameworks. For 1 a value of $8.25 \mathrm{emu} \mathrm{K} \mathrm{mol}^{-1}$ should be expected for one $\mathrm{Cu}^{\prime \prime}$ and one Gd"II cations, while in the case of 2 a value of 16.13 emu K mol${ }^{-1}$ is expected for one $\mathrm{Cu}^{\text {Il }}$ and two $\mathrm{Gd}^{\mathrm{III}}$ cations, considering for both compounds a $S_{\mathrm{Cu}(I I)}=1 / 2, S_{\mathrm{Gd}(I I I)}=7 / 2$ and $\mathrm{g}_{\mathrm{Cu} / \mathrm{Gd}}=2.0 .1$ and 2 show a constant $\chi_{\mathrm{m}} T$ value till $50 \mathrm{~K}$, indicating that a paramagnetic behavior is predominant in this temperature range. Nevertheless, below $50 \mathrm{~K}$ an abrupt increase of the $\chi_{\mathrm{m}}{ }^{\top}$ values was observed for both compounds, reaching a value of 13.06 and $19.46 \mathrm{emu} \mathrm{K} \mathrm{mol}^{-1}$ for 1 and 2 , respectively at $1.8 \mathrm{~K}$, indicating that a ferromagnetic behavior is displayed.

Additionally, field dependence of magnetization at $1.8,3,5$ and $8 \mathrm{~K}$ represented as $N_{B}$ vs $H$ is shown in Figure 9 for 1 and 2 . In both cases, the magnetization increases rapidly reaching a 
plateau of $8 \mu_{B}$ at $40 \mathrm{kOe}$ for 1 and $15 \mu_{B}$ at $50 \mathrm{kOe}$ for 2 , being consistent with the saturation values expected for the eight unpaired electrons of a core of $\mathrm{GdCu}^{\prime \prime} \mathrm{Cu}^{\prime}$ and fifteen unpaired electrons of a core of $\mathrm{Gd}_{2} \mathrm{Cu}^{\prime \prime} \mathrm{Cu}_{2}^{\prime}$.

Since both 1 and 2 are extended structures, the connectivity of the spin carriers is the key for the magnetic behavior analysis, i.e. to define the proper magnetic network. In the case of 1 , the structure can be reduced to $\mathrm{Cu}^{\prime \prime}-\mathrm{Gd}^{\mathrm{III}}$ chains linked through an anti-anti carboxylate bridge, where the Cu-Gd-chains are interconnected by $\mathrm{Cu}^{\prime}$ diamagnetic centers. However, the lack of an analytical model to fit the experimental magnetic data for a regular $\mathrm{Cu}-\mathrm{Gd}$ ferromagnetic chain, forces to use a simpler model to quantify the magnetic interaction between both cations. In this sense, considering the isotropic character of the $\mathrm{Cu}^{\text {II }}$ and $\mathrm{Gd}^{\text {III }}$ cations the magnetic data were analyzed using the spin-only Hamiltonian $\hat{H}=-2 J \hat{S}_{C u} \hat{S}_{G d}$, which describes the superexchange interaction between one $\mathrm{Cu}^{\prime \prime}$ and one $\mathrm{Gd}^{\prime \prime \prime}$ cation. Assuming that $\mathrm{Cu}^{\prime \prime}$ and $\mathrm{Gd}^{\text {III }}$ have equal $g$ values, the experimental data can be fitted with the following analytical expression ${ }^{78,79}$

$$
\chi^{\prime} T=\frac{4 N g^{2} \beta^{2} T}{k T}\left(\frac{7+15 e^{\left(\frac{8 J}{k T}\right)}}{7+9 e^{\left(\frac{8 J}{k T}\right)}}\right)
$$


Where $\mathrm{N}$ is the Avogadro number, $\mathrm{g}$ is the Lande factor, $\beta$ is the Bohr magneton, $\mathrm{k}$ is the Boltzmann constant and $J$ is the coupling constant. The best fit of the parameters was obtained using a $J=0.60 \mathrm{~cm}^{-1}$ and $\mathrm{g}=2.02$, with an agreement factor $R=4 \times 10^{-3}\left(R=\Sigma\left(\chi_{m} T_{\text {obs }}\right)-\left(\chi_{m} T_{\text {exp }}\right)\right.$ ${ }^{2} / \Sigma\left(\chi_{\mathrm{m}} \mathrm{T}_{\mathrm{obs}}\right)^{2}$

In the case of 2 , the compound presents a higher structural dimensionality, where the $\mathrm{Cu}^{\prime l}$ and Gd"I spin carriers are bridged by a carboxylate anion and both $\mathrm{Gd}-\mathrm{Gd}$ interactions can be produced by carboxylate or oxalate anions. However, it has been previously reported that due to the internal nature of the $4 f$ electrons, the Gd"I-Gd"II magnetic interaction are sufficient small to be neglected. ${ }^{80,81}$ Therefore, the magnetic network can be reduced to a more simple model considering only the interaction $\mathrm{Cu}^{\mathrm{II}}$-Gd"I hetero-spins carries. ${ }^{15}$ From a magnetic point of view, the extended 3D crystal network of 2 can be described as a linear trinuclear Gd"II-Cull-Gd"II core, with Gd"I-Cull centers connected through an anti-anticarboxylate bridge. This model leads to a spin-only Hamiltonian of $\hat{H}=-2 J \hat{S}_{G d 1} \hat{S}_{C u}-2 J \hat{S}_{C u} \hat{S}_{G d 2}$, which gives rise to the following analytical expression $^{82}$

$$
\chi_{m} T=\frac{N g^{2} \beta^{2} T A A}{2 k T \quad B B}
$$




$$
\begin{gathered}
A A=1+10 e^{\left(\frac{J}{k T}\right)}+e^{\left(-\frac{2 J}{k T}\right)}+35 e^{\left(\frac{2 J}{k T}\right)}+10 e^{\left(-\frac{3 J}{k T}\right)}+84 e^{\left(\frac{3 J}{k T}\right)}+35 e^{\left(-\frac{4 J}{k T}\right)}+165 e^{\left(\frac{4 J}{k T}\right)}+84 e^{\left(-\frac{5 J}{k T}\right)} \\
+286 e^{\left(\frac{5 J}{k T}\right)}+165 e^{\left(-\frac{6 J}{k T}\right)}+84 e^{\left(\frac{6 J}{k T}\right)}+286 e^{\left(-\frac{7 J}{k T}\right)}+680 e^{\left(\frac{7 J}{k T}\right)}+455 e^{\left(-\frac{8 J}{k T}\right)} \\
B B=2+4 e^{\left(\frac{J}{k T}\right)}+2 e^{\left(-\frac{2 J}{k T}\right)}+6 e^{\left(\frac{2 J}{k T}\right)}+4 e^{\left(-\frac{3 J}{k T}\right)}+8 e^{\left(\frac{3 J}{k T}\right)}+6 e^{\left(-\frac{4 J}{k T}\right)}+10 e^{\left(\frac{4 J}{k T}\right)}+8 e^{\left(-\frac{5 J}{k T}\right)}+12 e^{\left(\frac{5 J}{k T}\right)} \\
+10 e^{\left(-\frac{6 J}{k T}\right)}+14 e^{\left(\frac{6 J}{k T}\right)}+12 e^{\left(-\frac{7 J}{k T}\right)}+16 e^{\left(\frac{7 J}{k T}\right)}+14 e^{\left(-\frac{8 J}{k T}\right)}
\end{gathered}
$$

A nonlinear least-squares fit between $300-1.8 \mathrm{~K}$ leads to a value of $J=0.22 \mathrm{~cm}^{-1}, \mathrm{~g}=2.0$ $\left(R=8 \times 10^{-6}, R=\Sigma\left(\chi_{m} T_{\text {obs }}\right)-\left(\chi_{m} T_{\text {exp }}\right)^{2 / \Sigma}\left(\chi_{m} T_{\text {obs }}\right)^{2}\right)$. For 1 and 2 the positive $J$ value corroborates the ferromagnetic nature of the interaction between the Cull-Gd"II spin carriers as has been reported for analogous systems, ${ }^{16,83,84}$ however the quality of the fit are different. In 1 , the dinuclear model cannot reproduce the experimental data in the low temperature range, due to the $\chi_{m} T$ value at $1.8 \mathrm{~K}\left(13.06 \mathrm{emu} \mathrm{K} \mathrm{mol}^{-1}\right)$ is higher than the expected for a ferromagnetic coupled Cu-Gd isolated binuclear system $\left(10 \mathrm{emu} \mathrm{K} \mathrm{mol}^{-1}\right)$. This fact indicates that a higher magnetic dimensionality should be consider for 1, i.e. a genuine 1D magnetic network is observed. Meanwhile in 2, the experimental data are well reproduced in the whole temperature range by the use the trinuclear $\mathrm{Gd}-\mathrm{Cu}-\mathrm{Gd}$ model, indicating that in the case of 2 the $\mathrm{Gd}-\mathrm{Gd}$ interactions 
are small enough to be hidden by the stronger $\mathrm{Gd}-\mathrm{Cu}-\mathrm{Gd}$ interactions, thus behaving as isolated trinuclear cores in the crystal lattice.

Spin polarization has been postulated by Gatteschi et al. to explain this magnetic interaction between Cu"-Gd"II cations. ${ }^{85,86}$ This mechanism is based on the partial delocalization of the $3 d$ unpaired electron of the Cull toward the empty $6 s$ or $5 d$ orbitals of Gd"II with the same spin of the seven $f$ electrons, in order to obey Hund's rule. Thus, a ferromagnetic pathway can be established when a magnetic orbital of one paramagnetic site has a non-zero overlap with an empty orbital of the other site. ${ }^{87}$ Most of the studied Cull-Gd"l' systems are 0D complexes formed by dioxo bridges (alcoxo or phenoxo). The magneto-structural correlations show that planar conformation in Cu-dioxo-Gd moieties and shorter $\mathrm{Cu} \cdots \mathrm{Gd}$ distances lead to stronger ferromagnetic interactions. ${ }^{88}$ On the other hand, carboxylate bridges have been less studied since this group mediates weaker magnetic interactions than the oxo bridge due to the longer $\mathrm{Cu} \cdots \mathrm{Gd}$ distances; as far as we know no systematic studies have been made up to date. Regarding the different types of carboxylate bridges, the syn-anti conformation has been reported to mediate poor ${ }^{89}$ or null magnetic interaction between $\mathrm{Cu}^{\prime \prime}$ and $\mathrm{Gd}^{\prime \prime \prime},{ }^{90,91}$ while the antianti conformation produces weak ferromagnetic interactions. ${ }^{16,36}$ For example, Liu et al reported 
a 3D HCP $\left\{\left[\mathrm{GdCu}\left(\mathrm{L}^{1}\right)_{2}\left(\mathrm{~L}^{2}\right)\left(\mathrm{H}_{2} \mathrm{O}\right)_{2}\right] \cdot \mathrm{mH}_{2} \mathrm{O}\right\}_{\mathrm{n}}\left(\mathrm{H}_{2} \mathrm{~L}^{1}=\right.$ quinolinic acid, $\mathrm{HL}^{2}=$ nicotinic acid), in which the anti-anti carboxylate bridges of quinolinate and nicotinate ligands generate a $\mathrm{Cu} \cdots \mathrm{Gd}$ distance of $6.010 \AA$, with a ferromagnetic coupling of $J=0.426 \mathrm{~cm}^{-1} .92$ On the other hand, Zou et al. found a slightly stronger magnetic interaction of $J=1.30(3) \mathrm{cm}^{-1}$ between $\mathrm{Cu}^{\mathrm{II}}-\mathrm{Gd}^{\mathrm{III}}$ for a shorter inter-cation distance of $5.991 \AA$ in the $1 \mathrm{D}$ compound $\left[\mathrm{Gd}\left(\mathrm{H}_{2} \mathrm{O}\right)_{3}\left(\mathrm{NO}_{3}\right)(\mathrm{CuL})_{2}\right] \cdot \mathrm{H}_{2} \mathrm{O}\left(\mathrm{H}_{3} \mathrm{~L}=\right.$ glycylglycine-N-[1-(2-hydroxy, phenyl)-propylidene]). ${ }^{93}$ These facts are in agreement with that observed in 1 and 2, in which the shorter $\mathrm{Cu} \cdots \mathrm{Gd}=6.1378 \AA$ distance, present in 1 , produces a slightly higher magnetic coupling $\left(J=0.60 \mathrm{~cm}^{-1}\right)$ compared with the coupling constant in $2,(J=$ $0.22 \mathrm{~cm}^{-1}$ for a $\mathrm{Cu} \cdots \mathrm{Gd}=6.226 \AA$ ). Hence, beyond of the structural complexity that present 1 and 2 networks, the simplification of the structures leads to some interesting magneto-structural correlations.

\section{CONCLUDING REMARKS}

Despite the difficulty to include at the same time $\mathrm{Cu}^{\prime}$ and $\mathrm{Cu}^{\prime \prime}$ in an $3 d-4 f$ heterometallic extended network, two novel $\mathrm{Cu}^{\prime} / \mathrm{Cu}^{\prime \prime}-\mathrm{Gd}^{\prime \prime \prime} \quad \mathrm{HCP} \quad\left[\mathrm{Gd}\left(\mathrm{H}_{2} \mathrm{O}\right)_{4} \mathrm{Cu}^{\prime \prime} \mathrm{Cu}^{\prime}(\mathrm{IDC})_{2}\right] \quad 1$ and $\left[\mathrm{Gd}_{2}\left(\mathrm{H}_{2} \mathrm{O}\right)_{2}\left(\mathrm{C}_{2} \mathrm{O}_{4}\right)_{2} \mathrm{Cu}^{\prime \prime}(\mathrm{IDC})_{2} \mathrm{Cu}_{2}\left(4,4^{\prime}-\right.\right.$ bipy $\left.)\right] \cdot 4.5 \mathrm{H}_{2} \mathrm{O} 2$ have been successfully synthesized by solvothermal synthesis, using $1 \mathrm{H}$-imidazole-4,5-dicarboxylic acid $\left(\mathrm{H}_{3} \mid \mathrm{DC}\right)$ as principal N,O- 
bifunctional organic linker. Both 1 and 2 was obtained by the partial reduction of $\mathrm{Cu}^{\text {ll }}$ under autogenerated pressure, being the stabilization of $\mathrm{Cu}^{\prime}$ achieved only thanks to the coordination of $\mathrm{N}$-donor ligands. Interestingly, in the case of 1 , the simplicity of the chemical composition it is highlighted offering a path of synthesis where only one ligand is necessary to coordinate and stabilize three different cations. The proposed modification of the synthesis of 1 result successfully in the obtention of a second new mixed valence $3 d-4 f \mathrm{HCP} 2$, with a superior structural complexity. Compound 1 presents a honeycomb topology 2D network in which the crystal packing is achieved by hydrogen bonding between coordinated water molecules and the carboxylate groups. Meanwhile, in the case of 2 the addition of the extra organic linker permits to obtain a $3 D$ structure.

From a magnetic point of view, 1 and 2 behave as paramagnets at high temperature, showing ferromagnetic interactions from $50 \mathrm{~K}$ to $1.8 \mathrm{~K}$. It is important to point out that the use of simple analytical models was useful to determine which interactions are predominant, thus extracting the magnetic coupling constant for the principal exchange interaction between the $3 d-4 f$ spin carriers. Remarkably, the inclusion of $\mathrm{Cu}^{\prime} / \mathrm{Cu}^{\prime \prime}$ mixed valence cations in a $3 d-4 f$ coordination polymers offers a potential strategy to the rational design of new metal-organic materials, where 
the individual properties of the lanthanide cations can be used to the generation of new multifunctional materials.

\section{TABLES}

Table 1. Crystal data and structure refinement for 1 and 2

Table 2. Table 2 Hydrogen Bonds for 1

Table 1 Crystal data and structure refinement for 1 and 2

\begin{tabular}{lll}
\hline Compound code & 1 & 2
\end{tabular}

Compound formula $\quad\left[\mathrm{Gd}\left(\mathrm{H}_{2} \mathrm{O}\right)_{4} \mathrm{Cu}^{\prime \prime} \mathrm{Cu}^{\prime}(\mathrm{IDC})_{2}\right]$

$\left[\mathrm{Gd}_{2}\left(\mathrm{H}_{2} \mathrm{O}\right)_{2}\left(\mathrm{C}_{2} \mathrm{O}_{4}\right)_{2} \mathrm{Cu}^{\prime \prime}(\mathrm{IDC})_{2} \mathrm{Cu}_{2}\left(4,4{ }^{\prime}-\right.\right.$ bipy)] $4.5 \mathrm{H}_{2} \mathrm{O}$

Empirical formula

$\mathrm{C}_{10} \mathrm{H}_{10} \mathrm{Cu}_{2} \mathrm{GdN}_{4} \mathrm{O}_{12}$

$\mathrm{Cu}_{1.5} \mathrm{GdC}_{12} \mathrm{H}_{11.5} \mathrm{~N}_{3} \mathrm{O}_{11.25}$

Formula weight

662.53

630.34

Temperature/K

150

150

Crystal system

Triclinic

Triclinic

Space group

$P \overline{1}$

$P \overline{1}$

$a / \AA ̊$

6.6701(5)

8.5247(7)

$\mathrm{b} / \AA ̊$

11.3064(9)

9.6931(9)

$c / \AA ̊$

12.0027(11)

12.0429(11)

$\alpha /^{\circ}$

$62.710(3)$

102.413(3) 


\begin{tabular}{|c|c|c|}
\hline$\beta /^{\circ}$ & $82.646(3)$ & $102.608(3)$ \\
\hline $\mathrm{Y} /^{\circ}$ & $78.035(3)$ & 111.608(3) \\
\hline Volume/Å3 & $786.39(11)$ & $853.70(13)$ \\
\hline Z & 2 & 2 \\
\hline$\rho_{\text {cal }} \mathrm{cg} / \mathrm{cm}^{3}$ & 2.790 & 2.407 \\
\hline$\mu / \mathrm{mm}^{-1}$ & 6.930 & 5.769 \\
\hline$F(000)$ & 628.0 & 585.0 \\
\hline Crystal size $/ \mathrm{mm}^{3}$ & $0.15 \times 0.03 \times 0.025$ & $0.08 \times 0.05 \times 0.04$ \\
\hline Radiation & $\operatorname{MoKa}(\lambda=0.71073)$ & $\operatorname{MoKa}(\lambda=0.71073)$ \\
\hline $\begin{array}{l}2 \Theta \text { range for data } \\
\text { collection } /^{\circ}\end{array}$ & 4.112 to 55.024 & 4.78 to 55.064 \\
\hline Reflections collected & 3614 & 19557 \\
\hline Independent & $3614[$ Rint $=0.0191$, Rsigma & $3923[$ Rint $=0.0214$, Rsigma $=0.0170]$ \\
\hline reflections & $=0.0307]$ & \\
\hline $\begin{array}{l}\text { Data/restraints/para } \\
\text { meters }\end{array}$ & $3614 / 18 / 281$ & $3923 / 18 / 278$ \\
\hline Goodness-of-fit on $\mathrm{F}^{2}$ & 1.096 & 1.131 \\
\hline $\begin{array}{l}\text { Final } R \quad \text { indexes } \\
{[l>=2 \sigma(I)]}\end{array}$ & $\mathrm{R} 1=0.0192, \mathrm{wR} 2=0.0453$ & $\mathrm{R} 1=0.0232, \mathrm{wR} 2=0.0619$ \\
\hline $\begin{array}{l}\text { Final } R \text { indexes [all } \\
\text { data] }\end{array}$ & $\mathrm{R} 1=0.0234, \mathrm{wR} 2=0.0464$ & $\mathrm{R} 1=0.0251, \mathrm{wR} 2=0.0632$ \\
\hline
\end{tabular}




\begin{tabular}{lll}
\hline Largest diff. & $1.03 /-0.83$ & $1.39 /-1.40$ \\
peak/hole / e $\AA^{-3}$ & &
\end{tabular}

Table 2 Hydrogen Bonds for 1

\begin{tabular}{llllllc}
\hline $\mathrm{D}$ & $\mathrm{H}$ & $\mathrm{A}$ & $\mathrm{d}(\mathrm{D}-\mathrm{H}) / \AA$ & $\mathrm{d}(\mathrm{H}-\mathrm{A}) / \AA$ & $\mathrm{d}(\mathrm{D}-\mathrm{A}) / \AA$ & $\mathrm{D}-\mathrm{H}-\mathrm{A} /^{\circ}$ \\
O1W & $\mathrm{H} 1 \mathrm{~W} A$ & $\mathrm{O} 51$ & $0.825(9)$ & $1.916(15)$ & $2.721(3)$ & $165(4)$ \\
O1W & H1WB & O42 & $0.827(9)$ & $1.931(11)$ & $2.756(3)$ & $176(5)$ \\
O2W & H2WB & O43 & 0.89 & 1.85 & $2.683(3)$ & 155.4 \\
O3W & H3WB & 014 & 0.90 & 1.96 & $2.840(3)$ & 165.0
\end{tabular}

FIGURE CAPTIONS

Figure 1. Scheme of synthesis of 1 and 2.

Figure 2. Coordination modes of (a) IDC ${ }^{3-}$, (b) 4,4'-bipiridine and $\mathrm{C}_{2} \mathrm{O}_{4}^{2-}$ in 1 and 2.

Figure 3. Coordination environment of (a) Cu1, (b) Cu2 and (c) Gd1 cations present in 1.

Figure 4. (a) Hexagonal honeycomb 2D extended structure, (b) simplified structure of 1, (c) scheme for the $\left[\mathrm{Gd}\left(\mathrm{H}_{2} \mathrm{O}\right)_{4}\right]^{3+}$ tripod moiety inserted in a hexagonal cavity and (d) supramolecular packing of 1 layers through $\mathrm{H}$-bond. 
Figure 5. Coordination environment of (a) Cu1, (b) Cu2 and (c) Gd1 in 2.

Figure 6. View of the assembly of the extended structure of 2 through a axis, (a) in pink, Gd"Ioxalate based chains, in green, $\mathrm{Cu}^{\prime} / \mathrm{Cu}^{\prime \prime}$ mixed valence chains and (b) scheme of the connection between $\mathrm{Gd}^{\prime \prime \prime}$-oxalate and $\mathrm{Cu}^{\prime} / \mathrm{Cu}^{\prime \prime}$ through IDC ${ }^{3-}$ linking.

Figure 7. Thermogram between $25^{\circ}$ and $900^{\circ} \mathrm{C}$ under $\mathrm{N}_{2}$ atmosphere for 1 and 2 (inset) and in situ temperature-dependent X-ray diffraction (TDXD) under $\mathrm{N}_{2}$ atmosphere was performed for

1.

Figure 8. $\chi_{\mathrm{m}} \mathrm{T}$ vs $\mathrm{T}$ plot at $1 \mathrm{kOe}$ between 300 and $1.8 \mathrm{~K}$ for 1 and 2 . In the inset, scheme of the

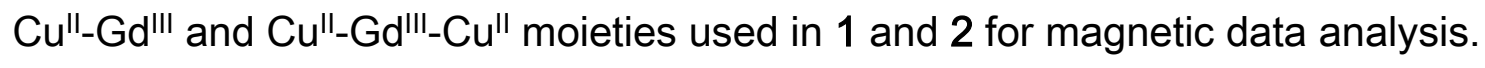

Figure 9. Isothermal magnetization represented by reduced magnetization $\left(N_{\beta}\right)$ at 1.8, 3, 5 and $8 \mathrm{~K}$ between 0-90 kOe for (a) 1 and (b) 2. 


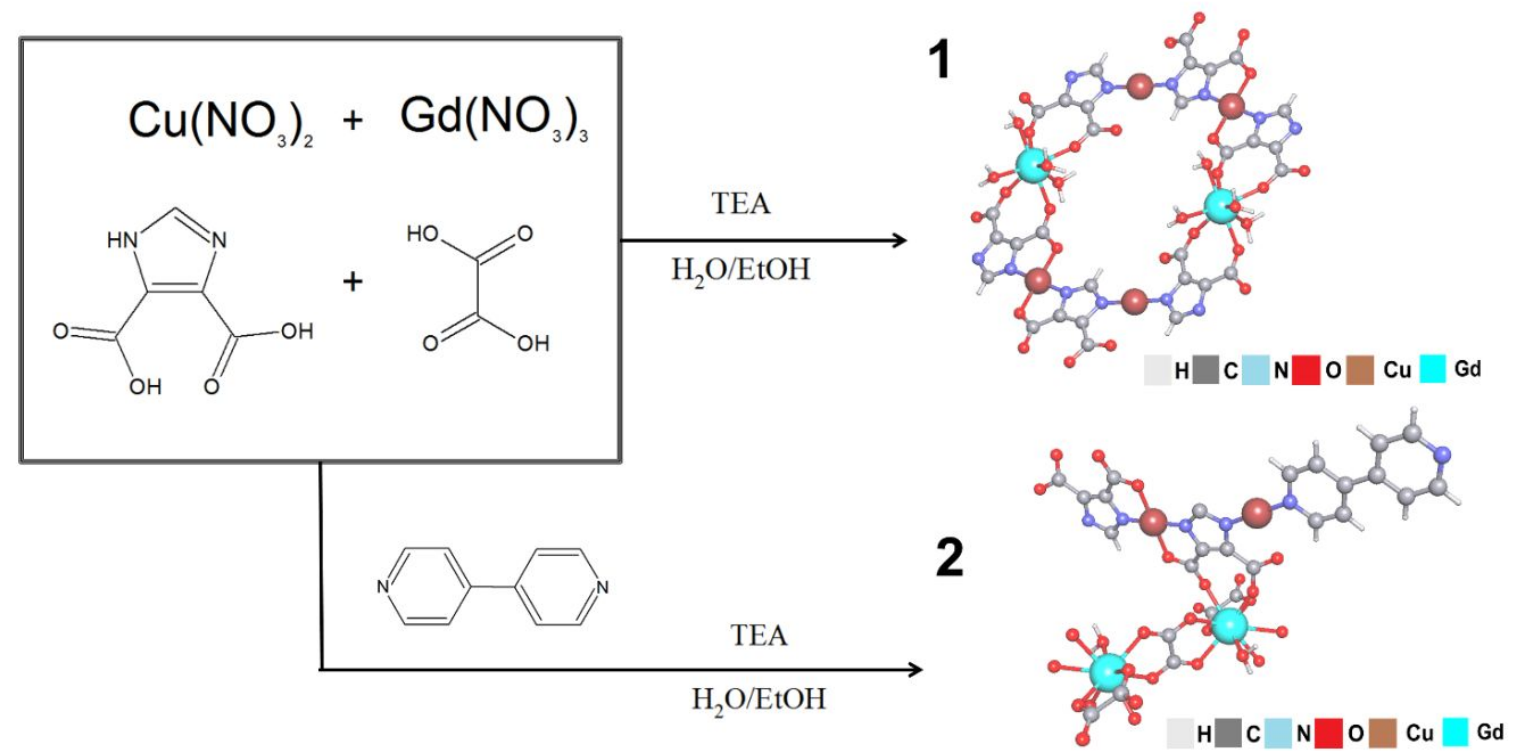

Figure 1
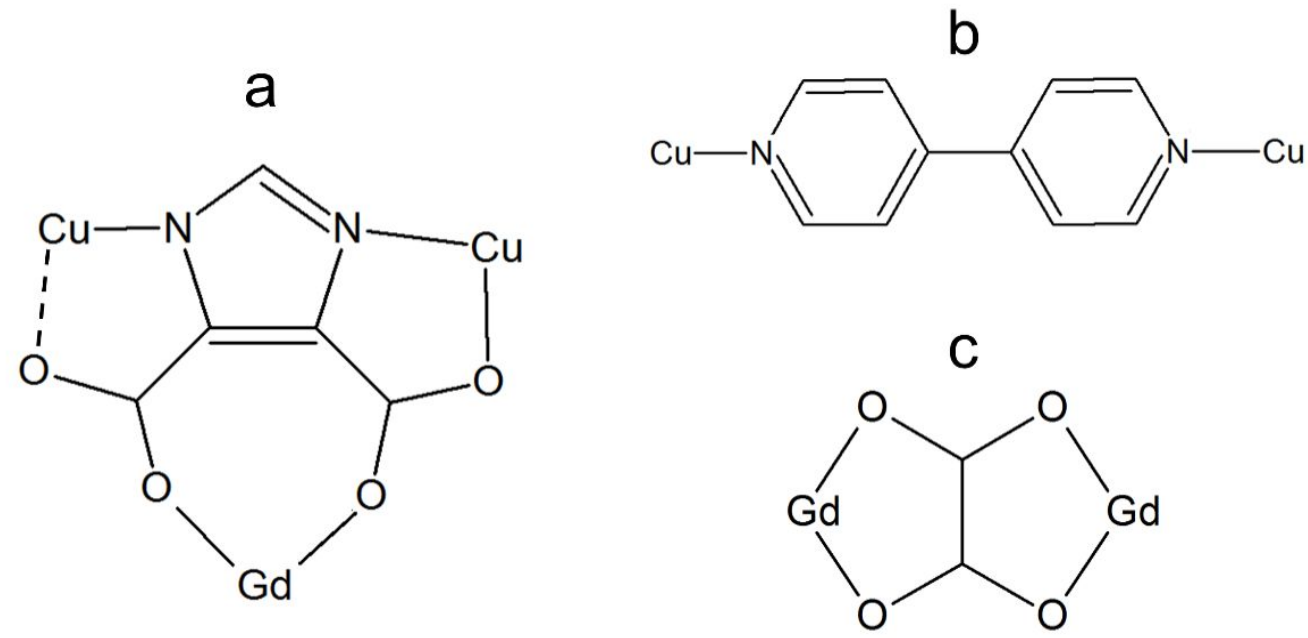

Figure 2 
a

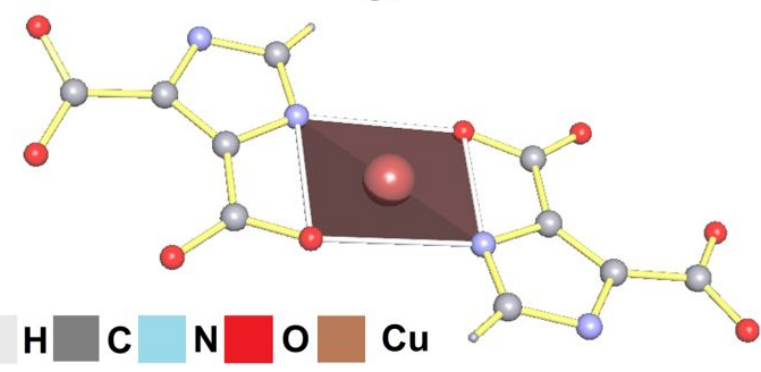

b

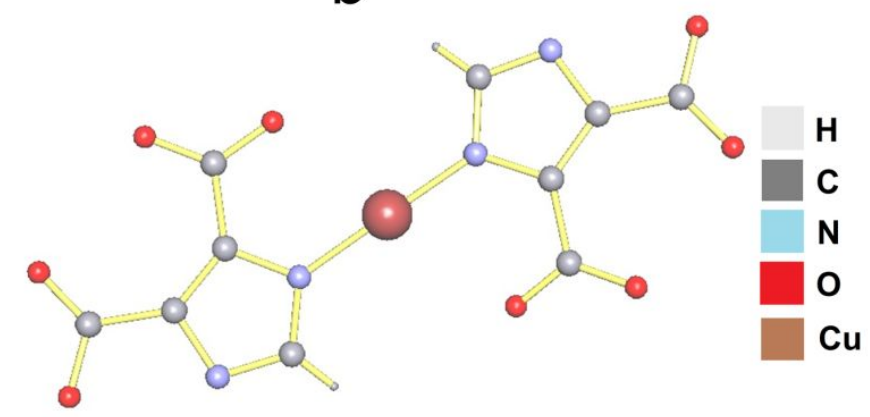

C
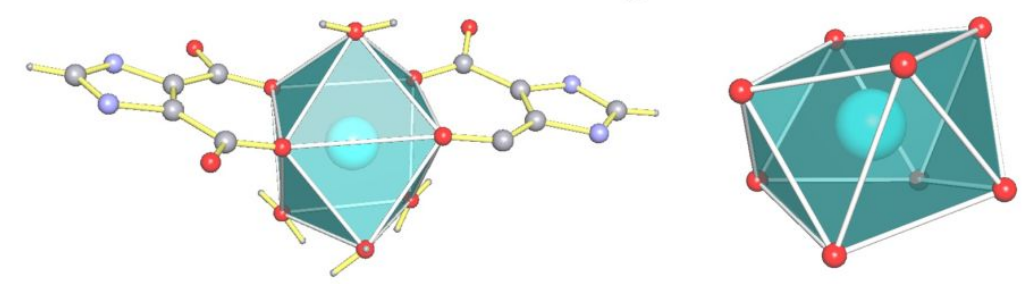

$\begin{array}{llllll}H & C & N & O & \text { Gd }\end{array}$

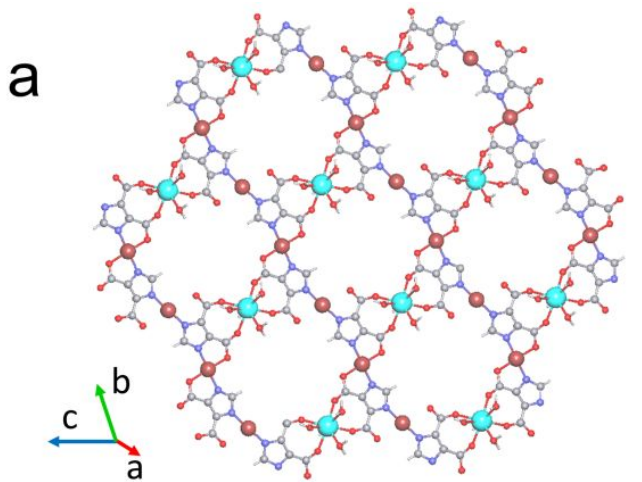

C

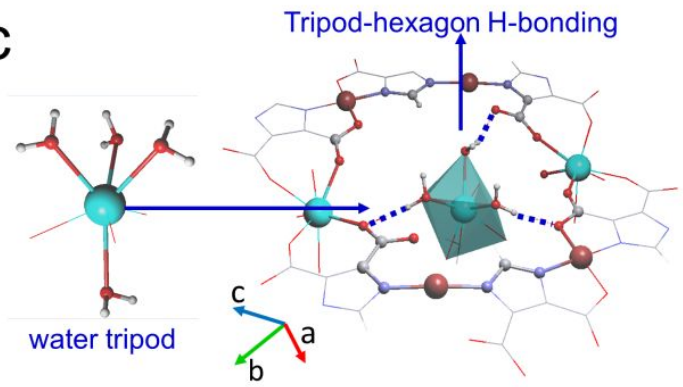

b

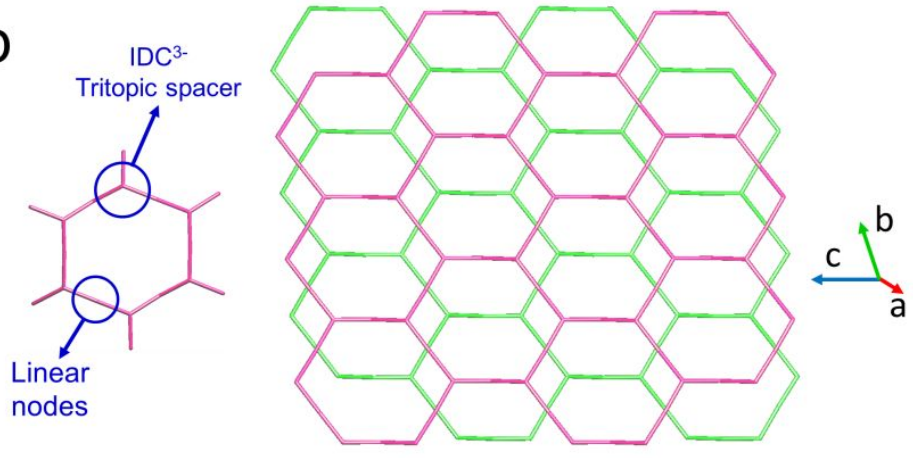

d

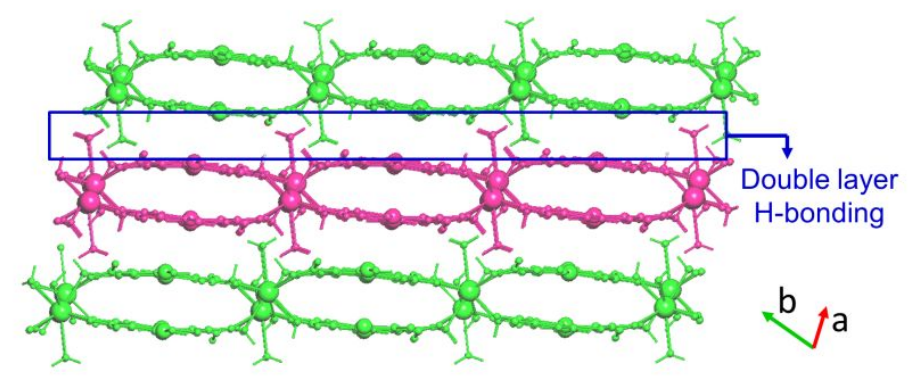

Figure 4 

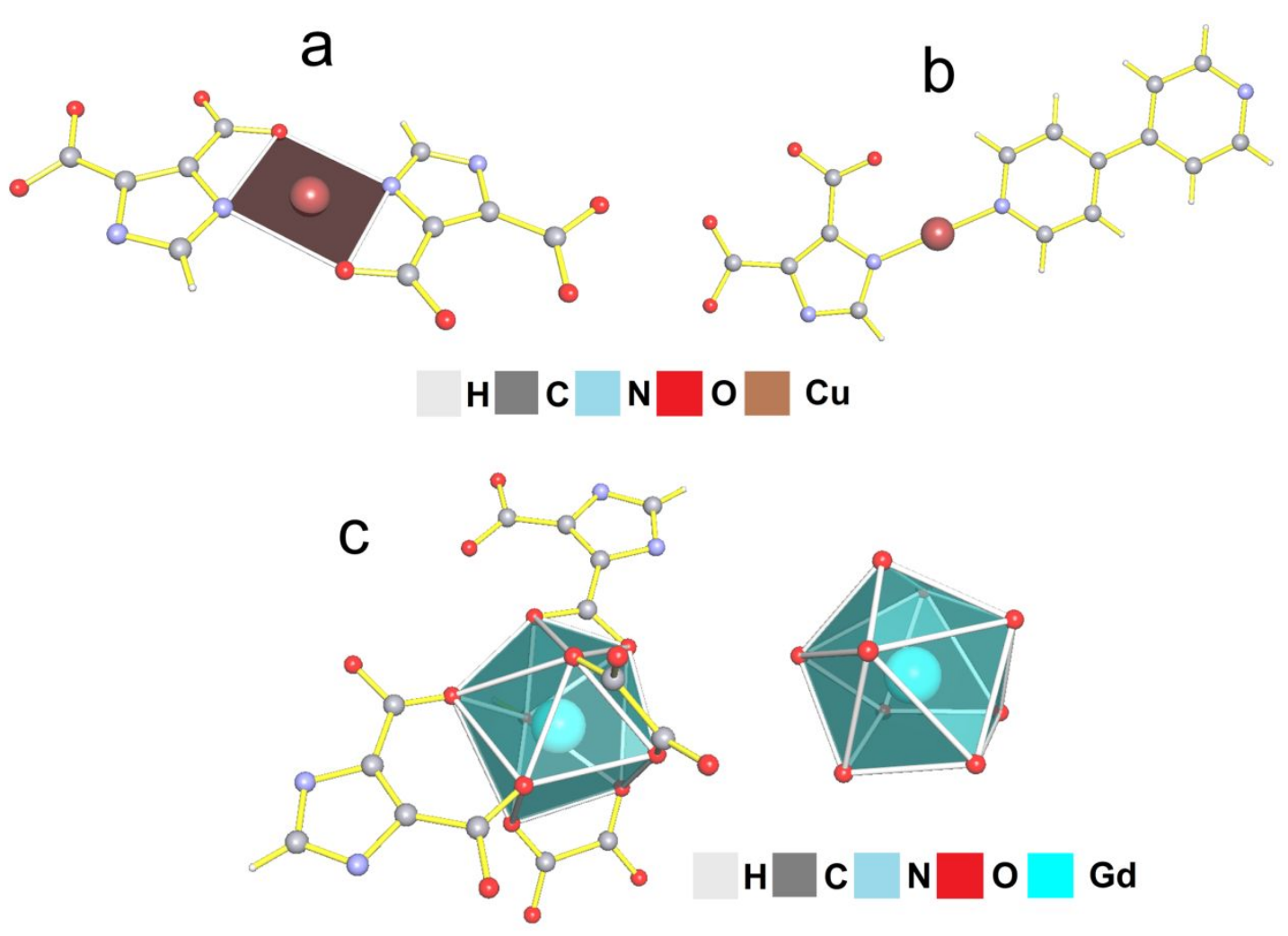

Figure 5
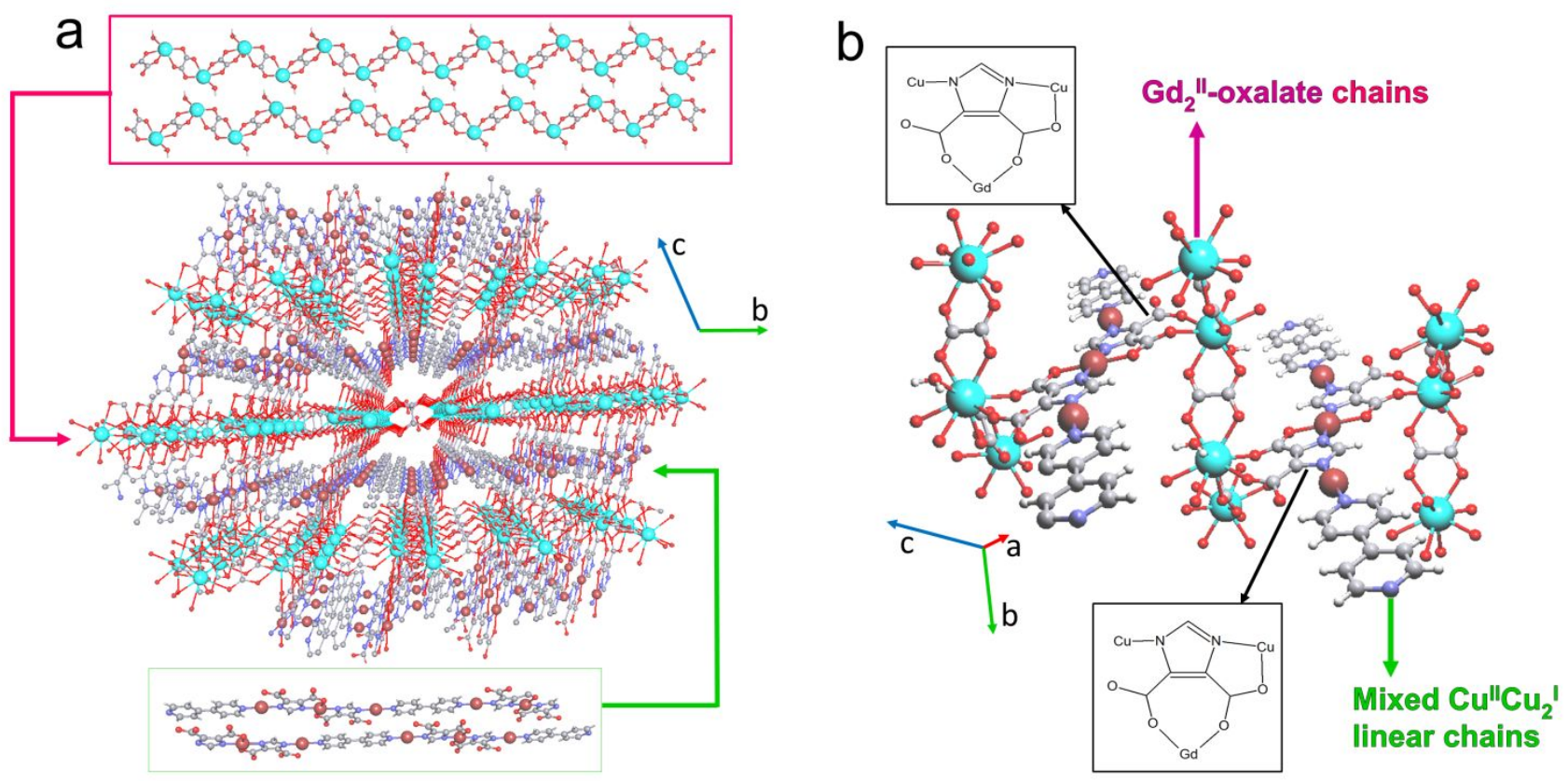

Figure 6 


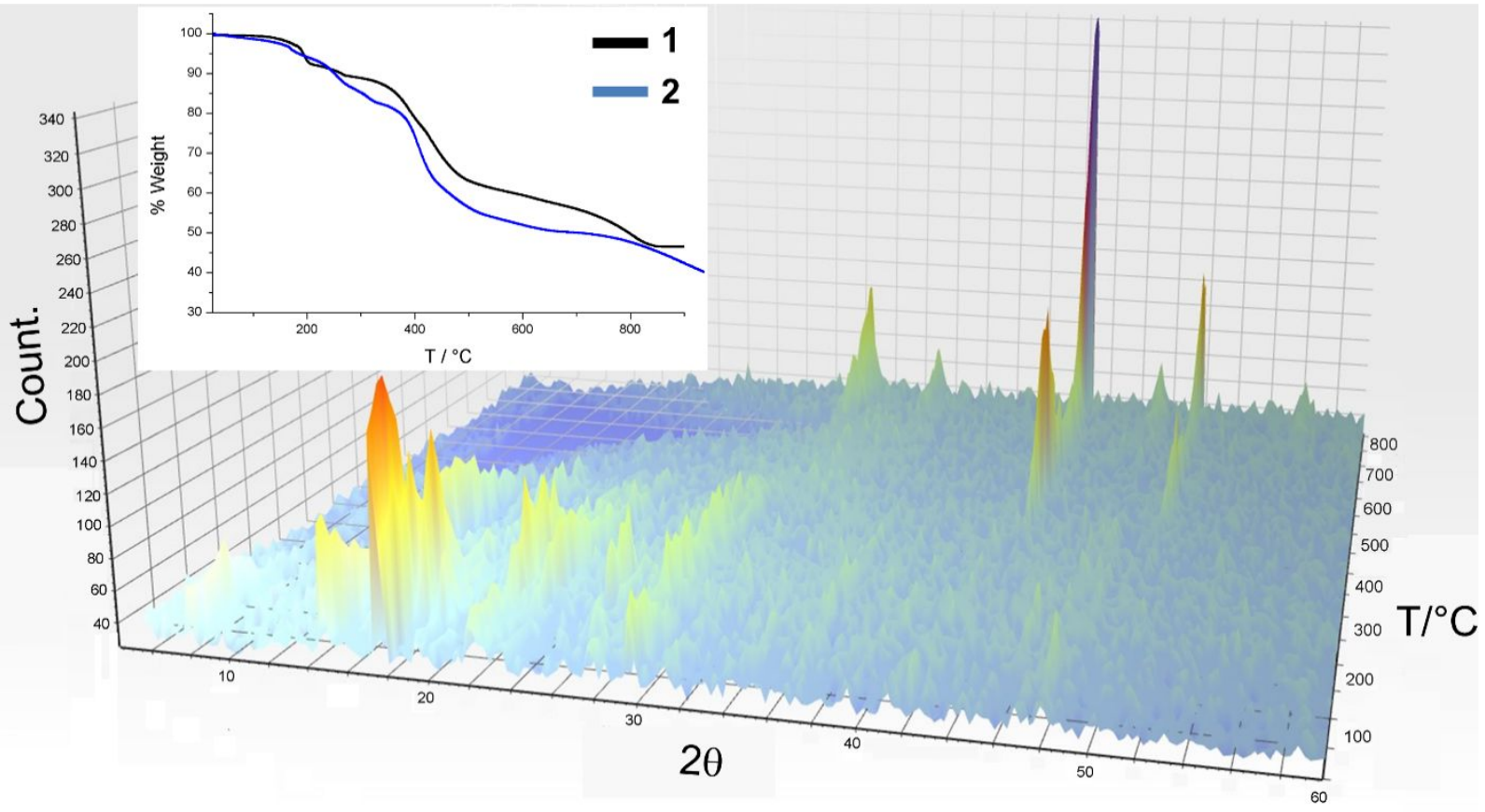

Figure 7
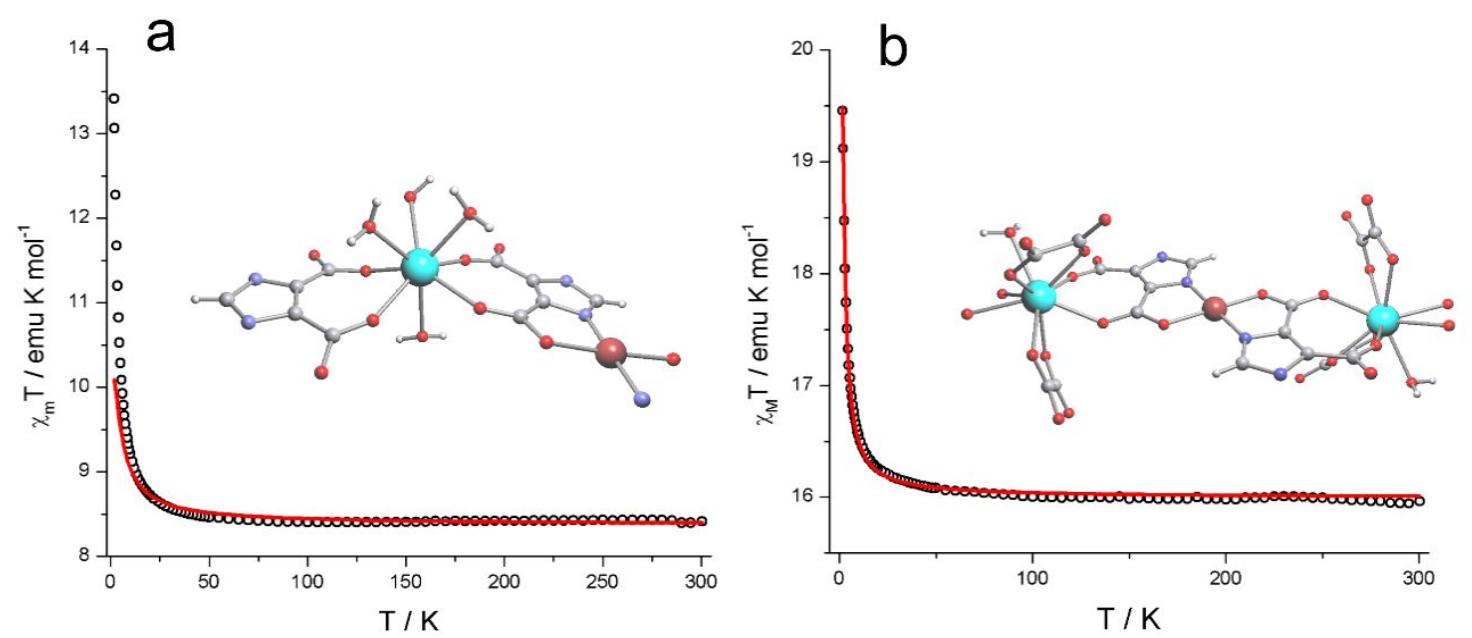

Figure 8 

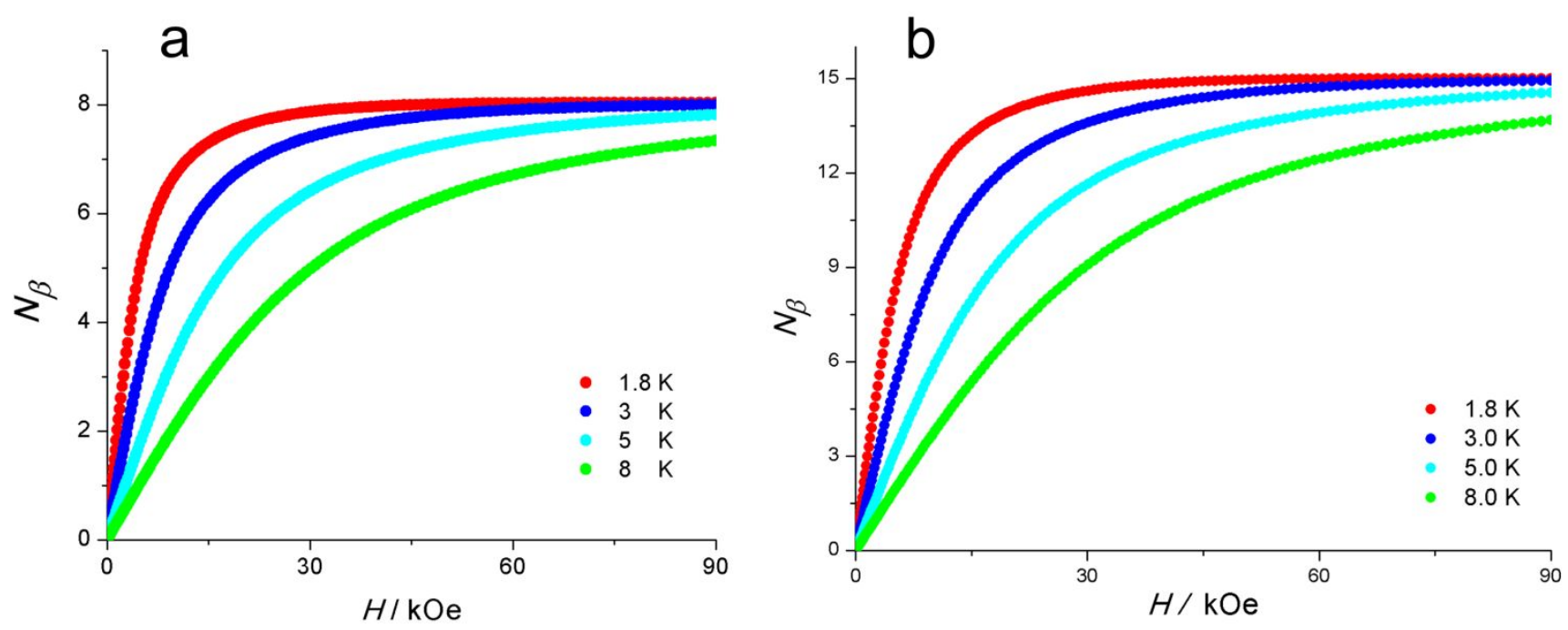

Figure 9

\section{ASSOCIATED CONTENT}

Supporting Information.

The following files are available free of charge, experimental and calculated Powder X-Ray diffraction pattern of 1 (Figure S1), UV-Vis spectra for 1 and 2 (Figure S2) and complete crystallographic refinament data for 1 and 2 (Table S1 and S2)

Accession Codes CCDC 1915837-1915838 contains the supplementary crystallographic data for this publication. These data can be obtained free of charge via www.ccdc.cam.ac.uk/data_request/cif, or by emailing data_request@ccdc.cam.ac.uk, or by 
contacting The Cambridge Crystallographic Data Centre, 12 Union Road, Cambridge CB2 1EZ,

UK; fax: +44 1223336033 .

\section{AUTHOR INFORMATION}

Corresponding Author

*V.P-G.: e-mail, vparedes@unab.cl; tel, +56-2-2661 5756.

Acknowledgements: The authors acknowledge FONDECYT 1170887, Proyecto Anillo

CONICYT ACT 1404 grant, CONICYT-FONDEQUIP/PPMS/EQM130086-UNAB, Chilean-

French International Associated Laboratory for Multifunctional Molecules and Materials-LIAM3-

CNRS $\mathrm{N}^{\circ} 1027$ and ECOS/CONICYT C15E02. Authors acknowledge CEDENNA,

Financiamiento Basal, FB0807. The authors also acknowledge the support of the Laboratory of Analyses of Solids (L.A.S-UNAB). REFERENCES

(1) Liu, H.; Kang, Y. an; Fan, Y. P.; Guo, F. S.; Liu, L.; Li, J. L.; Liu, P.; Wang, Y. Y. High Thermally and Chemically Stable Nickel(II) Coordination Polymers: Tentative Studies on Their Sorption, Catalysis, and Magnetism. Cryst. Growth Des. 2018, 19, 797-807. 
(2) Hao, X. M.; Qu, T. G.; Wang, H.; Guo, W. L.; Chen, F.; Wu, Y. B.; Yang, D.; Xu, Z. L. A

3D Porous Coordination Polymer Transformed from a 1D Nonporous Coordination

Polymer for Selectively Sensing of Diiodomethane. J. Solid State Chem. 2018, 268, 62-

66.

(3) Li, Y. M.; Li, X. F.; Wu, Y. Y.; Collins Wildman, D.; Hu, S. M.; Liu, Y.; Li, H. Y.; Zhao, X.

W.; Jin, L. Y.; Dang, D. Bin. Ni" , Mn" , and Co"l Coordination Polymers with 1,4-

Naphthalenedicarboxylic Acid Exhibiting Metamagnetic and Antiferromagnetic

Behaviors. Cryst. Growth Des. 2018, 18, 7541-7547.

(4) Wang, P.; Fan, R. Q.; Yang, Y. L.; Liu, X. R.; Xiao, P.; Li, X. Y.; Hasi, W.; Cao, W. W. 1-

D Helical Chain, 2-D Layered Network and 3-D Porous Lanthanide-Organic Frameworks

Based on Multiple Coordination Sites of Benzimidazole-5,6-Dicarboxylic Acid: Synthesis,

Crystal Structure, Photoluminescence and Thermal Stability. CrystEngComm 2013, 15,

4489-4506.

(5) Bing, Y.; Xu, N.; Shi, W.; Liu, K.; Cheng, P. Two Lanthanide(III)-Copper(II) Organic

Frameworks Based on $\left\{\mathrm{OLn}_{6}\right\}$ Clusters That Exhibited a Large Magnetocaloric Effect 
and Slow Relaxation of the Magnetization. Chem. Asian J. 2013, 8, 1412-1418.

(6) Dong, R. T.; Chen, X. L.; Cui, X.; Chen, S. S.; Shen, M. Y.; Li, C. W.; Li, Q. H.; Hu, M.

Y.; Huang, L. F.; Deng, H. Copper(I)-Lanthanide(III) Heterometallic Metal-Organic

Frameworks Constructed from 3-(3-Pyridyl)Acrylic Acid: Syntheses, Structures, and

Properties. CrystEngComm 2016, 18, 5547-5561.

(7) Li, X.; Huang, Y.; Cao, R. Three-Dimensional Pillared-Layer 3d-4f Heterometallic

Coordination Polymers with or without Halides. Cryst. Growth Des. 2012, 12, 3549-

3556.

(8) He, X.; Liu, Y.; Lv, Y.; Dong, Y.; Hu, G.; Zhou, S.; Xu, Y. L- And D-[LnZn(IN $\left.)_{3}\left(\mathrm{C}_{2} \mathrm{H}_{4} \mathrm{O}_{2}\right)\right]_{n}$

$(\mathrm{Ln}=\mathrm{Eu}, \mathrm{Sm}$, and Gd): Chiral Enantiomerically 3D 3d-4f Coordination Polymers

Constructed by Interesting Butterfly-like Building Units and -[Ln-O-Zn]n- Helices. Inorg.

Chem. 2016, 55, 2048-2054.

(9) Yang, T. H.; Silva, A. R.; Shi, F. N. Six New 3d-4f Heterometallic Coordination Polymers

Constructed from Pyrazole-Bridged Cu(II)Ln(III) Dinuclear Units. Dalt. Trans. 2013, 42,

$13997-14005$. 
(10) Yang, T. H.; Silva, A. R.; Fu, L.; Shi, F. N. Synthesis, Crystal Structure, and Catalytic

Properties of Porous 3d-4f Heterometallic Coordination Polymers Constructed from

Pyrazine-2,3-Dicarboxylic Acid. Zeitschrift für Anorg. und Allg. Chemie 2017, 643, $1801-$

1808.

(11) Shaowei, Z.; Peng, C. Recent Advances in the Construction of Lanthanide-Copper

Heterometallic Metal-Organic Frameworks. CrystEngComm 2015, 17, 4250-4271.

(12) Fedin, M. V; Veber, S. L.; Bagryanskaya, E. G.; Ovcharenko, V. I. Electron

Paramagnetic Resonance of Switchable Copper-Nitroxide-Based Molecular Magnets: An

Indispensable Tool for Intriguing Systems. Coord. Chem. Rev. 2015, 289-290, 341-356.

(13) Rentschler, E.; Gatteschi, D.; Cornia, A.; Fabretti, A. C.; Barra, A.L.; Shchegolikhina, O.

I.; Zhdanov, A. A. Molecule-Based Magnets: Ferro- and Antiferromagnetic Interactions in

Copper (II)-Polyorganosiloxanolate Clusters. Inorg. Chem. 1996, 1669, 4427-4431.

(14) Bencini, A.; Benelli, C.; Caneschi, A.; Carlin, R. L.; Dei, A.; Gatteschi, D. Crystal and

Molecular Structure of and Magnetic Coupling in Two Complexes Containing

Gadolinium(III) and Copper(II) Ions. J. Am. Chem. Soc. 1985, 107, 8128-8136. 
(15) Andruh, M.; Costes, J. P.; Diaz, C.; Gao, S. 3d-4f Combined Chemistry: Synthetic

Strategies and Magnetic Properties. Inorg. Chem. 2009, 48, 3342-3359.

(16) Manna, S. C.; Konar, S.; Zangrando, E.; Ribas, J.; Ray Chaudhuri, N. 3D Heterometallic (3d-4f) Coordination Polymers: A Ferromagnetic Interaction in a Gd(III)-Cu(II) Couple.

Polyhedron 2007, 26, 2507-2516.

(17) Li, Z. Y.; Wang, Y. X.; Zhu, J.; Liu, S. Q.; Xin, G.; Zhang, J. J.; Huang, H. Q.; Duan, C. Y. Three Series of 3d-4f Heterometallic Polymers Based on [ $\left.\mathrm{LnCu}_{6}\right]$ or $\left[\mathrm{Ln}_{6} \mathrm{Cu}_{24}\right]$ Clusters and Formate Bridges: Displaying Significant Magnetocaloric Effect. Cryst. Growth Des. 2013, 13, 3429-3437.

(18) Pavlishchuk, A. V; Kolotilov, S. V; Zeller, M.; Thompson, L. K.; Addison, A. W. Formation of Coordination Polymers or Discrete Adducts via Reactions of Gadolinium(III)-Copper(II) 15-Metallacrown-5 Complexes with Polycarboxylates: Synthesis, Structures and Magnetic Properties. Inorg. Chem. 2014, 53, 1320-1330.

(19) Yang, T. H.; Silva, A. R.; Shi, F. N. Six New 3d-4f Heterometallic Coordination Polymers Constructed from Pyrazole-Bridged Cu'Ln'II dinuclear Units. Dalt. Trans. 2013, 42, 
$13997-14005$.

(20) Xin, N.; Sun, Y. Q.; Zheng, Y. F.; Xu, Y. Y.; Gao, D. Z.; Zhang, G. Y. Seven 3d-4f

Coordination Polymers of Macrocyclic Oxamide with Polycarboxylates: Syntheses,

Crystal Structures and Magnetic Properties. J. Solid State Chem. 2016, 243, 267-27.

(21) Zeng, G.; Xing, S.; Wang, X.; Yang, Y.; Ma, D.; Liang, H.; Gao, L.; Hua, J.; Li, G.; Shi,

Z.; Feng S. 3d-4f Metal-Organic Framework with Dual Luminescent Centers That

Efficiently Discriminates the Isomer and Homologues of Small Organic Molecules. Inorg.

Chem. 2016, 55, 1089-1095.

(22) Xu, H.; Cao, C. S.; Xue, J. Z.; Xu, Y.; Zhai, B.; Zhao, B. A Cuprous/Lanthanide-Organic

Framework as the Luminescent Sensor of Hypochlorite. Chem. - A Eur. J. 2018, 24, 10296-10299.

(23) Wu, A. Q.; Guo, G. H.; Yang, C.; Zheng, F. K.; Liu, X.; Guo, G. C.; Huang, J. S.; Dong, Z. C.; Takano, Y. Extended Structures and Magnetic Properties of Lanthanide-Copper Complexes with Picolinic Acids as Bridging Ligands. Eur. J. Inorg. Chem. 2005, 10, 1947-1954. 
(24) Bo, Q. B.; Sun, Z. X.; Forsling, W. A New Family of 3D 3d-4f Heterometallic Frameworks

Comprising 1D Inorganic Lanthanide Ladders and Organic Cu'-Bipyridine Chains.

CrystEngComm 2008, 10, 232-238.

(25) Bo, Q. B.; Sun, G. X.; Geng, D. L. Novel Three-Dimensional Pillared-Layer Ln(III)-Cu(I)

Coordination Polymers Featuring Spindle-Shaped Heterometallic Building Units. Inorg.

Chem. 2010, 49, 561-571.

(26) Sun, Y. N.; Xiong, G.; Dragutan, V.; Dragutan, I.; Ding, F.; Sun, Y. G. Novel Luminescent Heterobimetallic Ln-Cu(I) 3D Coordination Polymers Based on 5-(4-Pyridyl) Isophthalic Acid as Heteroleptic Ligand. Synthesis and Structural Characterization. Inorg. Chem. Commun. 2015, 62, 103-106.

(27) Ay, B.; Karaca, S.; Yildiz, E.; Lopez, V.; Nanao, M. H.; Zubieta, J. In Situ Hydrothermal Syntheses, Structures and Photoluminescent Properties of Four Novel Metal-Organic Frameworks Constructed by Lanthanide ( $\mathrm{Ln}=\mathrm{Ce}(\mathrm{III}), \operatorname{Pr}(\mathrm{III}), \mathrm{Eu}(\mathrm{III}))$ and $\mathrm{Cu}(\mathrm{I})$ Metals with Flexible Dicarboxylate Acids and Piperazine-Based Ligands. J. Solid State Chem. 2016, $233,415-421$. 
(28) Zhu, Z. B.; Zeng, H. P. A 3-D Gd(III)-Cu(I) Coordination Polymer Based on Nicotinate and Oxalate Ligands: Synthesis, Crystal Structure, and Magnetic Properties. J. Coord. Chem. 2010, 63, 2097-2104.

(29) Wu, S. A Novel Three-Dimensional Hetero-Metallic Coordination Polymer: Poly[[diaquadi- $\mu_{3}$-chlorido- $\mu_{2}$-chlorido-tri- $\mu_{3}$-nicotinato-tricopper(I)gadolinium(III)] hemihydrate]. Acta Crystallogr. Sect. C Cryst. Struct. Commun. 2011, C67, 211-214.

(30) Cao, G. J.; Li, Q. L.; Rong, C.; Wang, Y. L. A Tubular One-Dimensional Polymer Constructed from Alternating Clusters of Europium(III)-Water and Copper(I) Chloride Bridged by 4-(Pyridin-4-yl)Benzoate. Acta Crystallogr. Sect. C Cryst. Struct. Commun. 2013, C69, 712-715.

(31) Fang, W. H.; Yang, G. Y. Three Pillared-Layer 3d-4f Heterometallic Frameworks Based on Tetranuclear Lanthanide Clusters. CrystEngComm 2013, 15, 4504-4512.

(32) Xia, C.; Xiong, G.; You, L.; Ren, B.; Wang, S.; Sun, Y. Synthesis, Crystal Structure, and Photoluminescent Properties of a Series of $\mathrm{Ln}^{\mathrm{III}}-\mathrm{Cu} \mathrm{u}^{\mathrm{l}}$ Heterometallic Coordination Polymers Based on $\mathrm{Cu}_{4} \mathrm{I}_{3}$ Clusters and Ln-Ina Rod Units. Aust. J. Chem. 2017, 70, 943- 
951.

(33) Fang, W. H.; Cheng, J. W.; Yang, G. Y. Two Series of Sandwich Frameworks Based on Two Different Kinds of Nanosized Lanthanide(III) and Copper(I) Wheel Cluster Units. Chem. - A Eur. J. 2014, 20, 2704-2711.

(34) Chen, H. M.; Hu, R. X.; Zhang, M. B. Heterometallic Coordination Polymers Constructed by Linear Ligands. Inorganica Chim. Acta 2011, 379, 34-39.

(35) Luo, F.; Che, Y. X.; Zheng, J. M. The First Self-Penetrating Topology Based on an Unusual $\alpha$-Po Net with Double Edges Constructed from a $12-$ Connected $\mathrm{Gd}_{2}\left(\mu_{2^{-}}\right.$ $\left.\mathrm{O}_{\text {carboxylate }}\right)_{2}\left(\mu_{2}-\mathrm{OH}_{2}\right)_{2}\left(\mu_{3}-\mathrm{OH}\right)_{2} \mathrm{Cu}_{2}$ Core. Cryst. Growth Des. 2006, 6, 2432-2434.

(36) Cruz, C.; Spodine, E.; Venegas-Yazigi, D.; Paredes-García, V. Cu(II)-Gd(III) 2DCoordination Polymer Based on Two Different Organic Linkers. Polyhedron 2017, 136, $117-124$.

(37) Cruz, C.; Spodine, E.; Vega, A.; Venegas-Yazigi, D.; Paredes Garcia, V. Novel 3d/4f Metal Organic Networks Containing Co(II) Chiral Chains. Cryst. Growth Des. 2016, 16 (4), 2173-2182. 
(38) Cruz, C.; Spodine, E.; Audebrand, N.; Venegas-Yazigi, D.; Paredes-García, V. Structural

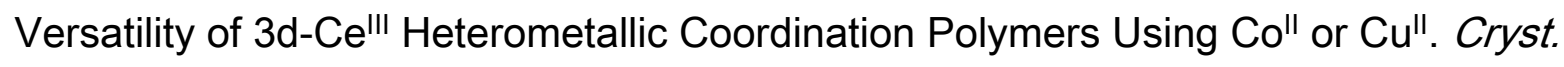

Growth Des. 2018, 18, 5155-5165.

(39) APEX3 V2016.1-0. APEX3 V2016.1-0, Bruker AXS Inc.: Wisconsin, USA 2016.

(40) SAINT V6.22. SAINT V6.22 Bruker AXS Inc.: Madison, WI, USA 2000.

(41) SADABS V2.05. SADABS V2.05 Bruker AXS Inc.: Madison, WI, USA 2001.

(42) Dolomanov, O. V.; Bourhis, L. J.; Gildea, R. J.; Howard, J. A. K.; Puschmann, H.

OLEX2: A Complete Structure Solution, Refinement and Analysis Program. J. Appl.

Crystallogr. 2009, 42, 339-341.

(43) Sheldrick, G. M. SHELXT - Integrated Space-Group and Crystal-Structure

Determination. Acta Crystallogr. Sect. A Found. Adv. 2015, A71, 3-8.

(44) Sheldrick, G. M. Crystal Structure Refinement with SHELXL. Acta Crystallogr. Sect. C Struct. Chem. 2015, C71, 3-8.

(45) Blatov, V.; Shevchenko, A. ToposPro, Program Package for Multipurpose 
Crystallochemical Analysis. ToposPro V5.0, program package for multipurpose crystallochemical analysis 2014.

(46) Bain, G. A.; Berry, J. F. Diamagnetic Corrections and Pascal's Constants. J. Chem. Educ. 2008, 85, 532-536.

(47) Llunell, M.; Casanova, D.; Cirera, J.; Alemany, P.; Alvarez, S. SHAPE V2.1. SHAPE V2.1, Departament de Química Física, Departament de Química Inorgànica, and Institut de Química Teòrica i Computacional, Universitat de Barcelona: Barcelona, España 2013.

(48) Truong, Q. D.; Kakihana, M. Hydrothermal Growth of Cross-Linked Hyperbranched Copper Dendrites Using Copper Oxalate Complex. J. Cryst. Growth 2012, 348, 65-70.

(49) Catalano, V. J.; Malwitz, M. A.; Etogo, A. O. Pyridine Substituted N-Heterocyclic Carbene Ligands as Supports for $\mathrm{Au}(\mathrm{I})-\mathrm{Ag}(\mathrm{I})$ Interactions: Formation of a Chiral Coordination Polymer. Inorg. Chem. 2004, 43, 5714-5724.

(50) Irwin, M. J.; Vittal, J.; Yap, G. ; Puddephatt, R. Linear Gold (I) Coordination Polymers: A Polymer with a Unique Sine Wave Conformation. J. Am. Chem. Soc. 1996, 7863, 
$13101-13102$.

(51) Chen, C. L.; Kang, A. B. S.; Su, C. Y. Recent Advances in Supramolecular Design and Assembly of Silver (I) Coordination Polymers. Aust. J. Chem. 2006, 59, 3-18.

(52) Tong, M. L.; Wu, Y. M.; Ru, J.; Chen, X. M.; Chang, H. C.; Kitagawa, S. PseudoPolyrotaxane and $\beta$-Sheet Layer-Based Three-Dimensional Coordination Polymers Constructed with Silver Salts and Flexible Pyridyl-Type Ligands. Inorg. Chem. 2002, 41, 4846-4848.

(53) Zhang, L. Y.; Lu, L. P.; Feng, S. S. A Two-Dimensional Mixed-Valence Cull/Cu' Coordination Polymer Constructed from 2-(Pyridin-3-yl)-1H-Imidazole-4,5-Dicarboxylate. Acta Crystallogr. Sect. C Struct. Chem. 2016, C72, 652-657.

(54) Visinescu, D.; Fabelo, O.; Ruiz-Pérez, C.; Lloret, F.; Julve, M, Synthesis, crystal structure and magnetic properties of a new cyanide-bridged mixed-valence copper(I)/copper(II) clathrate. Inorg. Chem. Comm. 2013, 52, 252-254.

(55) Fotouhi, L.; Dehghanpour, S.; Heravi, M.; Ardakani, M. Electrochemical Synthesis and Structural Characterization of a Novel Mixed-Valence Copper (I)-Copper (II) Complex: 
\{[Bis(Ethylenediamine) Copper (II)] Bis[Diiodocuprate (I)]\}. Molecules 2007, 12, 1410-

1419.

(56) De, S.; Chowdhury, S.; Naskar, J. P.; Drew, M. G. B.; Clérac, R.; Datta, D. A

Hexadecanuclear Copper(I)-Copper(II) Mixed-Valence Compound: Structure, Magnetic

Properties, Intervalence Charge Transfer, EPR, and NMR. Eur. J. Inorg. Chem. 2007,

23, 3695-3700.

(57) Zhu, Y.; Wang, W.; Guo, M.; Li, G.; Lu, H. An Unprecedented 1-D Mixed-Valence

$\mathrm{Cu}(\mathrm{II}) / \mathrm{Cu}(\mathrm{I})$ Metal-Organic Framework Bearing 2-Phenyl Imidazole Dicarboxylates.

Inorg. Chem. Acta 2011, 14, 1432-1435.

(58) Day, P.; Hush, N.; Clark, R. Mixed Valence: Origins and Developments. Philos. Trans.

R. Soc. $A$ 2008, 366, 5-14.

(59) Robin, M.; Day, P. Mixed Valence Chemistry-A Survey and Classification. Adv. Inorg.

Chem. Radiochem. 1967, 10, 247-422.

(60) Lu, W. G.; Jiang, L.; Feng, X. L.; Lu, T. B. Three 3D Coordination Polymers Constructed by $\mathrm{Cd}(\mathrm{II})$ and Zn(II) with Imidazole-4,5-Dicarboxylate and 4,4'-Bipyridyl Building Blocks. 
Cryst. Growth Des. 2006, 6, 564-571.

(61) Wang, Y. L.; Yuan, D. Q.; Bi, W. H.; Li, X.; Li, X. J.; Li, F.; Cao, R. Syntheses and

Characterizations of Two 3D Cobalt-Organic Frameworks from 2D Honeycomb Building

Blocks. Cryst. Growth Des. 2005, 5, 1849-1855.

(62) Beatty, A. M. Open-Framework Coordination Complexes from Hydrogen-Bonded

Networks: Toward Host/Guest Complexes. Coord. Chem. Rev. 2003, 246, 131-143.

(63) Zhang, J.; Xiong, R. G.; Chen, X. T.; Che, C. M.; Xue, Z.; You, X. Z. Two Luminescent

2D Layered Copper (I)-Olefin Coordination Polymers with High Thermal Stability.

Organometallics 2001, 20, 4118-4121.

(64) Hao, J.; Yu, B.; Hecke, K. Van; Cui, G. A Series of $d^{10}$ Metal Coordination Polymers

Based on a Flexible Bis (2-Methylbenzimidazole) Ligand and Different Carboxylates:

Synthesis, Structures, Photoluminescence and Catalytic Properties. CrystEngComm

2015, 7, 2279-2293.

(65) Abrahams, B. F.; Hoskins, B. F.; Michail, D. M.; Robson, R. Assembly of Porphyrin Building Blocks into Network Structures with Large Channels. Nature 1994, 369, 727- 
729.

(66) Dimos, A.; Tsaousis, D.; Michaelides, A.; Skoulika, S.; Golhen, S.; Ouahab, L.;

Didierjean, C.; Aubry, A. Microporous Rare Earth Coordination Polymers: Effect of Lanthanide Contraction on Crystal Architecture and Porosity. Chem. Mater. 2002, 14, $2616-2622$.

(67) Dhas, N. A.; Raj, C. P.; Gedanken, A. Synthesis, Characterization, and Properties of Metallic Copper Nanoparticles. Chem. Mater. 1998, 10, 1446-1452.

(68) Boita, J.; Nicolao, L.; Alves, M. C. M.; Morais, J. Controlled Growth of Metallic Copper Nanoparticles. New J. Chem. 2017, 41, 14478-14485.

(69) Kuzníková, L.; Dedková, K.; Pavelek, L.; Kupková, J.; Vána, R.; Rümmeli, M. H.; Kukutschová, J. Synthesis and Characterization of Gadolinium Oxide Nanocrystallites; IntechOpen, 2016.

(70) Armaroli, N.; Accorsi, G.; Cardinali, F.; Listorti, A. Photochemistry and Photophysics of Coordination Compounds: Copper. Topics in Current Chemistry, Photochemistry and Photophysics of Coordination Compounds. 2007, pp 69-115. 
(71) Xiong, Z.; Yuan, P.; Xie, Z.; Li, G. Three Transition-Metal Polymers from Imidazole

Dicarboxylates-Bearing Methoxyphenyl Groups: Syntheses, Crystal Structures and

Properties. Supramol. Chem. 2013, 26, 346-357.

(72) Manch, W.; Fernelius, W. C. The Structure and Spectra of Nickel(II) and Copper(II)

Complexes. J. Chem. Educ. 1961, 38, 192-201.

(73) Barbieri, A.; Accorsi, G.; Armaroli, N. Luminescent Complexes beyond the Platinum

Group: The $\mathrm{d}^{10}$ Avenue. Chem. Commun. 2008, 19, 2185-2193.

(74) Strasser, A.; Vogler, A.; Phosphorescence of gadolinium(III) chelates under ambient conditions, Inorg. Chim. Acta, 2004, 357, 2345-2348.

(75) Bünzli, J.; Piguet, C. Taking Advantage of Luminescent Lanthanide lons. Chem. Soc.

Rev. 2005, 34, 27-32.

(76) Cotton, S. Lanthanide and Actinide Chemistry; Interscience Publichers, John Wiley \&

Sons 2006, pp 70.

(77) Feng, S.; Ma, L.; Feng, G.; Jiao, Y.; Zhu, M. Dinuclear Copper (II) Complexes Hold by

Crab-Shaped Pincer Ligands: Syntheses, Structures, Luminescent and Magnetic 
Properties. J. Chem. Struct. 2014, 1059, 27-32.

(78) Costes, J. P.; Dahan, F.; Dupuis, A.; Laurent, J. P. A Genuine Example of a Discrete Bimetallic (Cu, Gd) Complex: Structural Determination and Magnetic Properties. Inorg. Chem. 1996, 35, 2400-2402.

(79) Koner, R.; Lee, G. H.; Wang, Y.; Wei, H. H.; Mohanta, S. Two New Diphenoxo-Bridged Discrete Dinuclear Cu"Gd"II Compounds with Cyclic Diimino Moieties: Syntheses, Structures, and Magnetic Properties. Eur. J. Inorg. Chem. 2005, 1500-1505.

(80) Cañadillas-Delgado, L.; Fabelo, O.; Pasán, J.; Delgado, F. S.; Lloret, F.; Julve, M.; RuizPérez, C. Intramolecular Ferro- and Antiferromagnetic Interactions in Oxo-Carboxylate Bridged Digadolinium(lii) Complexes. Dalt. Trans. 2010, 39, 7286.

(81) Cañadillas-Delgado, L.; Pasan, J.; Fabelo, O.; Hernandez-Molina, M.; Lloret, F.; Julve, M.; Ruiz-Pérez, C. Two- and Three-Dimensional Networks of Gadolinium(III) with Dicarboxylate Ligands: Synthesis, Crystal Structure, and Magnetic Properties. Inorg. Chem. 2006, 45, 10585-10594.

(82) Zhang, J.; Li, C.; Wang, J.; Zhu, M.; Li, L. Slow Magnetic Relaxation Behavior in Rare 
Ln-Cu-Ln Linear Trinuclear Complexes. Eur. J. Inorg. Chem. 2016, 2016, 1383-1388.

(83) Winpenny, R. The Structures and Magnetic Properties of Complexes Containing 3d- and 4f-Metals. Chem. Soc. Rev. 1998, 27, 447.

(84) Hamamatsu, T.; Matsumoto, N.; Re, N.; Mrozinski, J. Chiral Ferromagnetic Chain of Copper(II)-Gadolinium(III) Complex. Chem. Lett. 2009, 38, 762-763.

(85) Benelli, C.; Caneschi, A.; Gatteschi, D.; Guillou, O.; Pardi, L. Synthesis, Crystal Structure, and Magnetic Properties of Tetranuclear Complexes Containing ExchangeCoupled $\mathrm{Ln}_{2} \mathrm{Cu}_{2}$ (Ln = Gd, Dy) Species. Inorg. Chem. 1990, $29(26)$, 1750-1755.

(86) Andruh, M.; Ramade, I.; Codjovi, E.; Guillou, O.; Kahn, O.; Trombe, J. C. Crystal Structure and Magnetic Properties of $\left[\mathrm{Ln}_{2} \mathrm{Cu}_{4}\right]$ Hexanuclear Clusters Where Ln Mechanism of the Gd(III)-Cu(II) Magnetic Interaction. J. Am. Chem. Soc. 1993, 115, $1822-1829$.

(87) Benelli, C.; Gatteschi, D. Magnetism of Lanthanides in Molecular Materials with Transition-Metal lons and Organic Radicals. Chem. Rev. 2002, 102, 2369-2387. 
(88) Cirera, J.; Ruiz, E. Exchange Coupling in Cu"Gd"II dinuclear Complexes: A Theoretical Perspective. Comptes Rendus Chim. 2008, 11, 1227-1234.

(89) Chen, X.M.; Wu, Y.L.; Aubin, S. M. J.; Hendrickson, D. N. Synthesis, Structures, and Magnetic Properties of Carboxylate-Bridged Tetranuclear Copper(II)-Lanthanoid(III) Complexes $\left.\left[\mathrm{Cu}_{2} \mathrm{Ln}_{2} \text { (Betaine }\right)_{10}\left(\mathrm{H}_{2} \mathrm{O}\right)_{8}\right]\left(\mathrm{ClO}_{4}\right)_{10} \cdot 2 \mathrm{H}_{2} \mathrm{O}$ and $\left.\left[\mathrm{Cu}_{2} \mathrm{Ln}_{2} \text { (Betaine) }\right)_{12}\left(\mathrm{ClO}_{4}\right)_{2}\right]\left(\mathrm{ClO}_{4}\right)_{8}$. Inorg. Chem. 1998, 37, 6186-6191.

(90) Wu, B.; Zheng, Y.; Ng, S. W. Preparation, Structure and Magnetic Study of a New Linear 1-D Cu(II)-Gd(III) Coordination Polymer. J. Coord. Chem. 2008, 61, 3674-3678.

(91) Li, Y.; Zheng, F. K.; Zou, J. P.; Zou, W. Q.; Ma, H. W.; Guo, G. C.; Lu, C. Z.; Huang, J. S. A Unique 3-D 3d-4f Heterometallic Coordination Polymer with Double Betaine Ligand: Crystal Structure and Magnetic Properties. Inorg. Chem. Commun. 2007, 10, 787-791.

(92) Liu, S.; Song, W.; Xue, L.; Han, S.; Zeng, Y.; Wang, L.; Bu, X. Three New Cu(II)-Ln(III) Heterometallic Coordination Polymers Constructed from Quinolinic Acid and Nicotinic Acid: Synthesis, Structures, and Magnetic Properties. Sci. China Chem. 2012, 55, 1064 1072. 
(93) Zou, Y.; Yin, F.; Zhou, X. J.; Chen, J.; Meng, Q. J. A Cu"l-Gd"I-Cu"l Heterometallic

Coordination Polymer Constructed by Gadolinium(III) Ion and Copper(II) Schiff-Base

Building Block: Structure and Magnetic Property. Inorg. Chem. Commun. 2014, 45, 25-

29. 


\title{
For Table of Contents Use Only
}

\author{
Carlos Cruz, ${ }^{a, b}$ Francisco Rubio ${ }^{a, b}$ Diego Venegas-Yazigi, ${ }^{b, c}$ Nathalie Audebrand, ${ }^{d}$ Christophe \\ Calers, ${ }^{d}$ Evgenia Spodine ${ }^{b, e}$ and Verónica Paredes-García*a,b
}

a Universidad Andrés Bello, Facultad de Ciencias Exactas, Departamento de Ciencias Químicas, Santiago, Chile.

b CEDENNA, Santiago, Chile.

c Universidad de Santiago de Chile, Facultad de Química y Biología, Departamento de Ciencias de los Materiales, Santiago, Chile

d Univ Rennes, CNRS, ISCR (Institut des Sciences Chimiques de Rennes) - UMR 6226, F35000 Rennes, France

e Universidad de Chile, Facultad de Ciencias Químicas y Farmacéuticas, Departamento de Química Inorgánica y Analítica, Santiago, Chile.

TOC graphic 


\section{Synopsis}

Two new $\mathrm{Cu} / / \mathrm{Cu}^{\mathrm{II}}-\mathrm{Gd}^{\mathrm{III}}$ mixed valence heterometallic coordination polymers are reported, $\left[\mathrm{Gd}\left(\mathrm{H}_{2} \mathrm{O}\right)_{4} \mathrm{Cu}^{\mathrm{II}} \mathrm{Cu}^{\mathrm{I}}(\mathrm{IDC})_{2}\right] \mathbf{1}$ and $\left[\mathrm{Gd}_{2}\left(\mathrm{H}_{2} \mathrm{O}\right)_{2}\left(\mathrm{C}_{2} \mathrm{O}_{4}\right)_{2} \mathrm{Cu}^{\mathrm{II}}(\mathrm{IDC})_{2} \mathrm{Cu}_{2} \mathrm{I}_{2}\left(4,4^{\prime}-\right.\right.$ bipy $\left.)\right] \cdot 4.5 \mathrm{H}_{2} \mathrm{O}$ 2. Compound 1 present a $2 \mathrm{D}$ honeycomb network constructed by a single organic linker (IDC $\left.{ }^{3-}\right)$ while 2 present a 3D structure with three different organic ligands (IDC ${ }^{3-}, \mathrm{C}_{2} \mathrm{O}_{4}{ }^{2-}$ and 4,4'-bipy). Both 1 and 2 exhibit ferromagnetic interactions below $50 \mathrm{~K}$. 